\title{
Role of the surface intermediates in the activity and stability of basic mixed oxides in ethanol condensation
}

Jorge Quesada, Laura Faba, Eva Díaz and Salvador Ordóñez*

Department of Chemical and Environmental Engineering, University of Oviedo,

Oviedo 33006, Spain

KEYWORDS: Guerbet reaction, DRIFT spectroscopy, butanol, aldol condensation, deactivation

ABSTRACT: The gas-phase ethanol self-condensation catalyzed by $\mathrm{Mg}-\mathrm{Al}$ and $\mathrm{Mg}-\mathrm{Zr}$ mixed oxides is studied in this work. The highest conversion and 1-butanol (key product) selectivity is obtained with $\mathrm{Mg}-\mathrm{Al}$, mainly working at $673 \mathrm{~K}$ and with a WSHV of $7.9 \mathrm{~h}^{-1}$, whereas lower conversions and higher dehydration products are observed with $\mathrm{Mg}-\mathrm{Zr}$. The different activity of both materials is related to their surface properties concluding that, despite the complex mechanism, a good distribution of medium-strength basic-acid sites is compulsory to promote the 1-butanol production, whereas acid sites promote dehydration steps, yielding undesired products. The stability of these materials is also studied, by combining the evolution of product concentrations in the gas phase with changes in the catalytic surfaces, observed by spectroscopic techniques (DRIFT), during 8 hours. Both materials present a good stability at $673 \mathrm{~K}$, without significant changes in conversion or selectivities, whereas partial deactivation was produced at higher temperatures (more relevant in the case of $\mathrm{Mg}-\mathrm{Zr}$ ) due to the 
permanent adsorption of aldehydes and oxygenated oligomers and the subsequent blockage of the active sites.

\section{INTRODUCTION}

Bioethanol (obtained by fermentation from different biomass feedstocks ${ }^{1}$ ) is nowadays produced in large amounts, highlighting the United States production (14,806 millions of gallons per year), being around the $60 \%$ of the world global production. ${ }^{2}$ The large availability as well as its potential as reactant for different catalytic conversions justify the high interest for its upgrading as an alternative sustainable raw material, not only for obtaining biofuels, ${ }^{3-5}$ but also as a platform for the manufacture of other petrochemicals, such as butadiene, butanol or acetone ${ }^{6}$ Among the different technological alternatives, ${ }^{7}$ the chemo-catalytic route (following the Guerbet reaction) is considered as the most promising one, even above the biological ones. ${ }^{8}$ 1-Butanol is the most interesting condensation adduct that can be obtained from bioethanol. It has been proposed as renewable fuel, with better properties than the starting bioethanol (higher energetic density and less hydrophilic behavior). ${ }^{7}$ Besides, 1-butanol can be used as a direct solvent or as starting material for other chemicals production, like acrylic acid, acrylic esters, butyl glycol ether, butyl acetate, dibutyl-ether etc. ${ }^{9-12}$

First approaches for transforming bioethanol into higher alcohols (butanol, hexanol, etc.) were carried out in liquid phase, using alkali, alkaline-earth hydroxides, transition metal oxides and alkali metal salts as homogeneous catalysts. ${ }^{13,14}$ Considering the most accepted mechanism, ${ }^{5,9,15-17}$ the ethanol self-condensation is kinetically limited by a previous dehydrogenation step, yielding acetaldehyde. Working in gas phase allows reaching the temperatures needed at atmospheric pressure, being the most typical conditions considered in the last studies. ${ }^{18,19}$ 
The gas-phase ethanol condensation mechanism (Scheme 1), is a complex process involving different individual steps (dehydrogenations, dehydrations, aldol condensation, hydrogenations) catalyzed by different active sites. The appropriate tuning of the catalytic properties, mainly in terms of the acidity-basicity distribution, would allow shifting the reaction to one or other reaction products. Thus, different catalysts have been used in the ethanol upgrading in order to obtain a specific product, such as metal oxides (i.e.: $\mathrm{MgO}$ catalyst; ethanol conversion 7.9\%; 1-butanol selectivity $40 \%$; $\mathrm{T}=653 \mathrm{~K}$ ), ${ }^{20-23}$ metal mixed oxides (i.e.: $\mathrm{MgAlO}_{\mathrm{x}}$ catalyst; $10-20 \%$ ethanol conversion; 3-5\% 1-butanol yield; $\mathrm{T}=573 \mathrm{~K}),{ }^{9,15}$ transition metal in the presence of basic compounds (i.e.: $\mathrm{CuMgAlO}$ catalyst; $4.1 \%$ ethanol conversion; $40.3 \%$ 1-butanol selectivity; $\mathrm{T}=473 \mathrm{~K}$ ), ${ }^{10,24}$ and hydroxyapatites (i.e.: hydroxyapatite $\mathrm{Ca} / \mathrm{P}$ ratio $=1.67$ catalyst; $8.2 \%$ ethanol conversion; $81.7 \%$ 1-butanol selectivity; $\mathrm{T}=573 \mathrm{~K}) .^{5,25-27}$

Despite the promising results of some of these materials, there are not systematic studies about the stability of heterogeneous materials in this reaction. Only few references report deactivation effects leading to selectivity changes with time on stream in continuous processes, but not providing any mechanistic justification. ${ }^{5,18}$ Deeper studies about other reactions conclude that the dynamics of the catalytic surface (changes in morphology and physico-chemical properties) is the key point to analyze the deactivation, using different techniques that can provide very useful information (physisorption, oxidation at temperature programmed, X-ray diffraction, etc.) about these chantes. In addition to these characterization techniques, Diffuse Reflectance Infrared Fourier Transform Spectroscopy (DRIFT) provides relevant information about the interaction of reactants, products and intermediates with the catalyst surface. ${ }^{28-31}$ This technique allows analyzing the evolution chemical moieties adsorbed on the 
catalytic surface, being possible to identify the intermediates or final products present in these interactions.

The main aim of this work is to analyze the stability of mixed oxides in the gas-phase ethanol condensation. Considering two different mixed oxides ( $\mathrm{Mg}-\mathrm{Zr}$ and $\mathrm{Mg}-\mathrm{Al})$ the reaction conditions were optimized to enhance the 1-butanol yield. The results obtained are related to the different surface properties of these materials, identifying the active sites controllinng the reaction. The stability and deactivation causes were then analyzed considering the optimum conditions previously determined for both materials. Using different characterization techniques as well as the DRIFT spectroscopy, and comparing the data with the reaction results, the evolution of different compounds in the surface is analyzed and correlated to the activity loses, comparing the behavior of two materials with different surface chemistry.

\section{EXPERIMENTAL METHODS}

2.1. Catalysts preparation. $\mathrm{Mg}-\mathrm{Al}$ mixed oxide $(\mathrm{Mg} / \mathrm{Al}=3)$ were obtained by the calcination of the corresponding hydrotalcites. The hydrotalcites were synthesized by co-precipitation of the $\mathrm{Mg}$ and $\mathrm{Al}$ nitrates at low supersaturation under sonication, following the procedure previously optimized by León et al. ${ }^{15}$ The gel was precipitated by increasing the $\mathrm{pH}$ to 10 and it was aged at $353 \mathrm{~K}$ for 24 hours. The solid phase was then isolated by centrifugation, washed with deionized water to $\mathrm{pH} 7$ and dried at $383 \mathrm{~K}$ for 24 hours. The mixed oxide was obtained by the thermal treatment under air flow of the corresponding hydrotalcites from 293 to $973 \mathrm{~K}$ with a rate of $5 \mathrm{~K} \cdot \mathrm{min}^{-1}$, holding this temperature for 5 hours.

$\mathrm{Mg}-\mathrm{Zr}$ mixed oxide was prepared from nitrate precursors using the sol-gel method detailed in our previous work. ${ }^{32}$ The gel was aged at $353 \mathrm{~K}$ during 24 hours, filtered, 
washed to $\mathrm{pH} 7$ and dried at $383 \mathrm{~K}$ for 24 hours. Finally, the mixed oxide was obtained by thermal treatment in helium flow, following a temperature program from 293 to $873 \mathrm{~K}$ with a rate of $5 \mathrm{~K} \cdot \mathrm{min}^{-1}$ and holding the final temperature during 3 hours.

2.2. Fresh catalysts characterization. Morphologic parameters were analyzed by $\mathrm{N}_{2}$ physisorption at $77 \mathrm{~K}$ in a Micromeritics ASAP 2020 by using the Brunauer-Emmett-Teller (BET) method to calculate the surface area, and the Barret-Joyner-Halenda (BJH) method to determine pore volume and diameter.

Basicity and acidity were determined by temperature programmed desorption (TPD) technique, using a Micromeritics 2900 TPD/TPR. In both cases, $20 \mathrm{mg}$ of sample were pre-treated in $\mathrm{He}$ flow and saturated with $\mathrm{CO}_{2}$ or $\mathrm{NH}_{3}$ to measure the basicity or acidity, respectively. The evolution of $\mathrm{CO}_{2}$ and $\mathrm{NH}_{3}$ signals were monitored in a Pfeiffer Vacuum Omnistar Prisma mass spectrometer while the temperature was increased at $2.5 \mathrm{~K} \cdot \mathrm{min}^{-1}$ from 298 to 973 or $873 \mathrm{~K}$, for $\mathrm{Mg}$-Al or $\mathrm{Mg}$-Zr, respectively.

The crystallographic structure of the mixed oxides was determined X-ray diffraction (XRD) using a Philips PW 1710 diffractometer, working with a $\mathrm{CuK}_{\alpha}$ line $(1.54 \AA)$ in the $2 \theta$ range between 5 and $80^{\circ}$, at a scanning rate of $2^{\circ} \cdot \mathrm{min}^{-1}$.

The surface composition of the samples was determined by X-ray photoelectron spectroscopy (XPS), using a SPECS system equipped with a Hemispherical Phoibos detector operating in a constant pass of energy, with $\mathrm{MgK}_{\alpha}$ radiation $(\mathrm{h} v=1253.6 \mathrm{eV})$. The samples were fixed to the sample holder with a carbon adhesive tape. The background pressure in the analysis chamber was kept below $4 \cdot 10^{-9}$ mbar during data acquisition. As samples are non-conducting, surface neutralization during measurements was required. 
2.3. Catalytic activity studies. Ethanol conversion experiments were performed between 473 and $723 \mathrm{~K}$ (with an interval of $50 \mathrm{~K}$ ) in a $0.4 \mathrm{~cm}$ i.d. U-shaped fixed bed quartz reactor placed in a controlled electric furnace. The catalyst (100-250 mg as function of the reaction; $250-355 \mu \mathrm{m}$ ) was placed over a plug of quartz wool and a thermocouple was placed inside the catalyst bed. Solid was pre-treated at $773 \mathrm{~K}$ for 1 hour in helium flow before each reaction. Absolute ethanol was injected by a syringepump in the helium flow, inducing the vaporization in situ, obtaining a $32 \mathrm{vol} . \%$ of ethanol, fed to the reactor at $0.02 \mathrm{~L} \cdot \mathrm{min}^{-1}(\mathrm{STP})$, with values of weight hourly space velocity (WHSV) from 4.7 to $11.8 \mathrm{~h}^{-1}$. Outgoing gases were on-line analyzed by gas chromatography using a HP6890 Plus, equipped with a flame ionization detector (FID). A TRB-5MS capillary column $(30 \mathrm{~m}, 0.25 \mathrm{~mm})$ was used as stationary phase. The identification of each compound was carried out using commercial standards and corroborated by GC-MS (Shimadzu QP-2010) using the same column and methodology than in the GC-FID.

Conversions (x) were calculated from the ethanol concentration at the reactor inlet and outlet. Selectivities $(\varphi)$ were calculated as the ratio between the concentration of each compound and the sum of the concentration of all the reaction products (considering the carbon atoms of each compound). In order to better analyze the activity, yields ( $\eta$ ) for different products were also considered, according to the following equation:

$$
\eta_{\mathrm{i}}=\mathrm{x} \cdot \varphi_{\mathrm{i}}
$$

Carbon balances were checked by comparing the total amount of carbon atoms at the reactor inlet and outlet, considering only the identified products. 
DRIFT spectroscopy was carried out using a Thermo Nicolet Nexus FT-IR equipped with a Smart Collector Accessory and a MCT/A detector, configured to record with a resolution of $4 \mathrm{~cm}^{-1}$ and to collect $60 \mathrm{scan} /$ spectrum. The catalyst sample $(20 \mathrm{mg})$ was placed inside the catalytic chamber where the temperature was controlled by a thermocouple. Samples were pre-treated at $773 \mathrm{~K}$ for $1 \mathrm{~h}$ in helium flow. Spectra were recorded in the $4000-650 \mathrm{~cm}^{-1}$ wavenumber range, after subtraction of the $\mathrm{KBr}$ standard background. All the signals were converted into Kubelka-Munk units to obtain semi-quantitative results. Spectra were collected at the same temperatures as in the reactor in order to compare the evolution of both gas and solid phase. The identification of each band was obtained by TPD-DRIFT spectroscopy. In these experiments, spectra were collected in He flow after a previous saturation step (30 min) using the probe molecules and a bubbler.

2.4. Catalytic stability studies. Catalyst stability was studied at temperatures of 673 and $723 \mathrm{~K}$ in the same experimental setup described above for the reaction studies. Conversion, selectivities and carbon balances evolution were followed as a function of time on stream analyzing the gas-phase for $8 \mathrm{~h}$ by gas chromatography. DRIFT spectroscopy measurements were recorded at 673 and $723 \mathrm{~K}$ each $10 \mathrm{~min}$ during $8 \mathrm{~h}$ for both $\mathrm{Mg}-\mathrm{Al}$ and $\mathrm{M}-\mathrm{Zr}$ catalysts.

Solids obtained after 8 hours of reaction at $723 \mathrm{~K}$ were homogenized and analyzed in a TG-SC instrument (Setaram, Sensys) using $\alpha$-alumina as inert reference material. Samples $(20 \mathrm{mg})$ were treated in a nitrogen flow $\left(20 \mathrm{~mL} \cdot \mathrm{min}^{-1}\right)$ with a temperature program of $5 \mathrm{~K} \cdot \mathrm{min}^{-1}$ from 298 to $923 \mathrm{~K}$. Changes in the crystallographic structure and surface area of these catalysts were studied by analyzing the spent samples using the same equipment and conditions than for the fresh catalysts. Additionally, $150 \mathrm{mg}$ of the 
spent materials were added to $2 \mathrm{~mL}$ of tetrahydrofuran and the liquid phases were analyzed by GC-MS after sonication for $30 \mathrm{~min}$ at room temperature.

\section{RESULTS AND DISCUSSION}

3.1. Reaction studies. First studies were carried out to identify the best reaction conditions, analyzing the behavior of $\mathrm{Mg}-\mathrm{Al}$ at different temperatures and different WHSV. The effect of the WHSV on catalyst performance (ethanol conversion and 1butanol yield) is depicted in Figure 1. The external mass transfer coefficient and the internal diffusivity (evaluated from Thiele modulus $(\Phi)$ ) were calculated in order to discard the presence of diffusional effects. Results obtained were compared with the limit values considered by Davis et al. ${ }^{33}$ Taking into account that same particle size was used in all the studies $(250-355 \mu \mathrm{m})$, the reaction temperature is the only operation parameter to be considered (the influence of the WHSV is negligible). Studies were carried out considering the maximum conversion observed (53\%, most adverse case) obtaining values of external mass transfer effect almost seven orders of magnitude lower than the limit to consider this effect as relevant. Regarding to the Thiele modulus, it is lower than 0.02 for all the performed experiments. As consequence, mass transference limitations were discarded and results can be directly related to the activity of this material.

As expected, ethanol conversion increases at increasing temperatures, being more evident the influence of the catalytic mass at temperatures over $623 \mathrm{~K}$, reaching maximums over $52 \%$ at $723 \mathrm{~K}$. At these conditions, the obtained carbon balances were in all the cases above $70 \%\left(82.6,73.2,80.1\right.$ and $75.1 \%$ for $11.8,7.9,5.9$ and $4.7 \mathrm{~h}^{-1}$, respectively). The GC-MS analyses corroborate that these values are due to the presence of different unsaturated alcohols, olefins and aromatics obtained as side products of the main mechanism. In order to identify the best operation conditions, butanol yields must 
be also considered. Values obtained in the range $623-723 \mathrm{~K}$ were the highest in all the cases, reaching the maximum values at $673 \mathrm{~K}(6.7,11.7,12.3$ and $12.7 \%$ with 11.8 , 7.9, 5.9 and $4.7 \mathrm{~h}^{-1}$, respectively). Regardless the space velocity, the yield decreases after this maximum, indicating that main reaction is not favored at the highest temperatures.

In order to gain further understanding on the reaction mechanism, Figure 2 shows the gas-phase analyses for the reaction catalyzed by $150 \mathrm{mg}\left(\mathrm{WSHV}=7.9 \mathrm{~h}^{-1}\right)$, in terms of ethanol conversion, carbon balance and evolution of the selectivity for the different compounds involved in the reaction. Similar trends were obtained at the other WHSV considered, being the profiles included as Supporting Information (Figure S1). As expected, conversion increases at increasing temperature, reaching values higher than $50 \%$ at $723 \mathrm{~K}$. Selectivities evolution is congruent with the accepted mechanism (Scheme 1). Thus, acetaldehyde (first intermediate) is the main product (66\%) at the lowest temperature, decreasing as temperature increases, reaching values lower than $32 \%$ at $723 \mathrm{~K}$. The relevance of the two primary side reactions (formation of ethylene and diethyl ether from ethanol) increases at the highest considered temperatures. However, the selectivity of diethyl-ether never reaches values higher than $2 \%$, whereas more than $35 \%$ of ethylene was obtained at the same conditions. Concerning to the main condensed intermediates (labelled as C-butenal-, E-butanal- and D-crotyl alcoholin Scheme 1), they were detected with very low selectivities in all the cases, being only relevant the selectivities of two final products: 1-butanol (the desired one) and 1,3-butadiene. At all the reaction conditions tested, 1-butanol selectivities were always higher than $20 \%$, reaching a maximum at $623 \mathrm{~K}$, with a $37.1 \%$ selectivity. Finally, the selectivity of 1,3-butadiene increases mainly at the highest temperatures, with a final value of $5.7 \%$ at $723 \mathrm{~K}$. The decrease in the carbon balance closure as the temperature 
increases (from $90 \%$ at $473 \mathrm{~K}$ to $63.5 \%$ at $723 \mathrm{~K}$ ) can be explained by the formation of different undesired products. At high temperatures, the Guerbet reaction can produce higher alcohols (mainly with an even number of carbon) and also the role of dehydration reactions is more relevant, yielding water. ${ }^{34,35}$ In the same way, C-C bond cleavage reactions are more likely to take place at the highest temperatures ${ }^{35}$. In good agreement with this lateral reactions, propanone, pentanol, hexenol and other alcohols or aldehydes and aromatic compounds were detected by GC-MS.

The distribution of quantifiable minor reaction products is detailed in Figure 3. In global terms, two maxima are detected (at 523 and $723 \mathrm{~K}$ ), but corresponding to very different situations. Despite the reaction conditions, crotonaldehyde is not observed at quantifiable amounts, indicating that the first hydrogenation of this compound is fast. However, the resulting crotonaldehyde hydrogenation product (crotyl alcohol or butanal) is strongly conditioned by the reaction temperature. At low temperatures, prevails the crotyl alcohol (selectivities close to $10 \%$ ), whereas almost $5 \%$ of butanal is obtained at $723 \mathrm{~K}$. Considering that both steps are hydrogenation reactions, two different mechanisms are suggested. The first one (from crotonaldehyde to crotyl alcohol) is promoted by the Meerwein-Ponndorf-Verley (MPV) reduction. On the other hand, the second route (to obtain the butanal) implies the hydrogenation of one $\mathrm{C}=\mathrm{C}$ double bond. This step needs requires the hydrogen released in the ethanol dehydrogenation. Experimental results suggest that the higher polarity of the interaction between the aldehyde and the catalytic surface enhances the role of the MPV mechanism, mainly at the lowest temperatures. This analysis is not so evident at higher temperatures in which the relevance of the equilibrium between butanal and 1-butanol (hydrogenation-dehydrogenation) is more relevant. 
Results obtained with the $\mathrm{Mg}-\mathrm{Al}$ were compared with the activity of $\mathrm{Mg}-\mathrm{Zr}$, a mixed oxide with a tested activity in aldol condensation. ${ }^{32}$ Figure 4 shows the evolution of conversion and selectivities of main products as function of the temperature working at $7.9 \mathrm{~h}^{-1}$. In general terms, conversion values are always lower than those obtained with $\mathrm{Mg}-\mathrm{Al}$ at same conditions, observing also a lower influence of the temperature, except at the highest temperature (623 to $723 \mathrm{~K}$ ). These conversion values were used to compare the activation energies as well as the pre-exponential factors obtained with both materials, considering that the disappearance of ethanol follows an apparent first order kinetics. The activation energy values obtained were 38.8 and $44.1 \mathrm{~kJ} \cdot \mathrm{mol}^{-1}$, for $\mathrm{Mg}-\mathrm{Al}$ and $\mathrm{Mg}-\mathrm{Zr}$ respectively, whereas the pre-exponential factors were $1.60 \cdot 10^{-3}$ and $2.76 \cdot 10^{-3} \mathrm{~m}^{3} \cdot \mathrm{s}^{-1} \cdot \mathrm{kg} \mathrm{cat}^{-1}$, respectively, justifying the higher activity of $\mathrm{Mg}-\mathrm{Al}$ by its lower activation energy. These values are congruent with data previously reported for this type of reactions, as for example $37 \mathrm{~kJ} \cdot \mathrm{mol}^{-1}$ for the acetaldehyde aldol condensation catalyzed by $\mathrm{TiO}_{2},{ }^{36}$ or $42 \mathrm{~kJ} \cdot \mathrm{mol}^{-1}$ for the reaction of ethanol to 1,3-butadiene catalyzed by metal-promoted magnesia silicate catalyst. ${ }^{37}$

Carbon balances obtained with $\mathrm{Mg}-\mathrm{Zr}$ were in all the cases higher than $64 \%$, with a decreasing profile congruent with the presence of lateral reactions at the highest temperatures. Taking into account that this decrease is more marked with $\mathrm{Mg}-\mathrm{Zr}$, it suggests a higher relevance of these side condensations, obtaining a plethora of alcohols and aldehydes in the GC-MS analysis. Concerning to the 1-butanol yield, similar trend was also observed, but the maximum selectivity (at intermediate temperatures) was considerably lower $(2.4 \%$ at $673 \mathrm{~K})$. At high temperatures, the amount of ethylene (undesired product) was significantly higher with $\mathrm{Mg}-\mathrm{Zr}(60 \%$ at $723 \mathrm{~K})$. This compound was not observed at lower temperatures, in good agreement with the behavior previously observed by Di Cosimo et al., ${ }^{9}$ with other Mg-Al mixed oxides. In 
the same way, the amount of diethyl-ether (other side product that was no significantly observed with $\mathrm{Mg}-\mathrm{Al}$ ) reached selectivities higher than $11.5 \%$ when $\mathrm{Mg}-\mathrm{Zr}$ was used as catalysts (at $723 \mathrm{~K}$ ). Finally, the selectivity of 1,3-butadiene was very similar in both cases, and only significant at the highest temperatures (5.6\%). Minority compounds are also detailed in the Figure 3. Comparing these results with those obtained with $\mathrm{Mg}-\mathrm{Al}$, higher temperatures are needed to detect these products when $\mathrm{Mg}-\mathrm{Zr}$ is used, highlighting the diethyl ether as the main one $(11.8 \%$ at $723 \mathrm{~K})$. Concerning to the other compounds considered, similar trends were obtained but at higher temperatures and with lower selectivities.

3.2. Surface chemistry. In order to gain further understanding on reaction mechanism, the evolution of the different species adsorbed on the catalytic surface was followed using IR spectroscopy. Figure 5 shows the spectra recorded at the same reaction conditions when $\mathrm{Mg}-\mathrm{Al}$ (Figure 5a) or $\mathrm{Mg}-\mathrm{Zr}$ (Figure 5b) were used as catalyst in order to determine the different adsorption modes of ethanol and their reaction products. The vibration mode of each adsorption band has been assigned according to results proposed by Shimanouchi ${ }^{38}$ and summarized in Table S1. In general terms, and with both materials, the intensities of most of the bands decrease with the temperature. This fact is congruent with the exothermicity of the adsorption process. Besides, this decrease is usually also associated with a slight displacement of the maximum, suggesting that there is more than one molecule adsorbed by the same functional group.

As it could be expected, main bands are associated to the formation of surface alkoxides (presumably ethanol but with some signals in common with other products, see Table S1), highlighting the signals observed at $1050 \mathrm{~cm}^{-1}$ and at $940 \mathrm{~cm}^{-1}$. The first one is identified as the $\mathrm{CO}$ stretching mode. This signal decreases sharply as the temperature 
increases, mainly in the case of $\mathrm{Mg}$-Al, being almost negligible at $723 \mathrm{~K}$. In the case of $\mathrm{Mg}-\mathrm{Zr}$, this decrease is softer, being the intensity still relevant at temperatures above $673 \mathrm{~K}$. This different behavior is congruent with the results in gas phase and the highest ethanol conversion observed with the $\mathrm{Mg}-\mathrm{Al}$. The signal at $1050 \mathrm{~cm}^{-1}$ is also relevant in the adsorption of other chemicals, such as crotyl alcohol, butanol and diethyl ether. In any case, the total disappearance at the temperatures in which the selectivity of these compounds is higher suggests that these compounds are not permanently adsorbed on the catalytic surface by this functional group. The second band related to the ethanol is centered on $940 \mathrm{~cm}^{-1}$, related to $\mathrm{CH}_{3}$ rocking and $\mathrm{C}-\mathrm{H}$ bending vibration modes present in different molecules involved in this reaction. In the case of $\mathrm{Mg}-\mathrm{Al}$, this peak is the main one at low temperatures, decreasing at higher ones, but keeping almost constant the maximum position. This suggests that this peak is related to only one compound, ethanol. On the other hand, this band is wider and has less resolution in the case of $\mathrm{Mg}-\mathrm{Zr}$, without a clear evolution with the temperature, suggesting that this band is not directly related to the ethanol but to other unsaturated compounds (crotonaldehyde, crotyl alcohol, 1,3-butadiene).

There is a complex area band around 1300 to $1800 \mathrm{~cm}^{-1}$ in which absorption of different species are overlapped. The band at $1380 \mathrm{~cm}^{-1}$ is identified as the $\mathrm{C}-\mathrm{H}$ bending mode of aldehydes. The high intensity of this band at low temperatures in the $\mathrm{Mg}-\mathrm{Al}$ is congruent with the highest activity of this material, being associated to the presence of aldehyde (first intermediate of the main reaction). The area of this peak decreases at medium temperatures (congruent with the advance of the reaction) and the maximum slightly moves to higher wavenumbers, indicating the adsorption of other carbonyls with higher molecular weight (crotonaldehyde and butanal). These results suggest that at low temperatures the adsorption prevails over the desorption and the final products 
are not detected in the gas phase despite that ethanol conversion observed. Signals around $1595 \mathrm{~cm}^{-1}$ are related to the water, ${ }^{38}$ produced during the dehydration of ethanol and other intermediates. The highest intensity observed in the spectra of $\mathrm{Mg}-\mathrm{Zr}$, mainly at high temperatures, is in good agreement with the gas-phase results, with more than $60 \%$ of ethylene. Two minor-role bands at 1660 and $1740 \mathrm{~cm}^{-1}$ appear only at the highest temperatures. These wavenumbers are identified to the $\mathrm{C}=\mathrm{C}$ and $\mathrm{C}=\mathrm{O}$ stretching modes of crotonaldehyde and crotyl alcohol, and crotonaldehyde and butanal, respectively. The highest intensity observed with $\mathrm{Mg}-\mathrm{Zr}$ suggests a permanent adsorption of these compounds (their yields in gas phase was always lower than $3 \%$ ), making more difficult their reaction to obtain the 1-butanol.

The presence of side-reaction that produce $\mathrm{C}_{3}, \mathrm{C}_{5}$, and other odd carbon number unsaturated alcohols and olefins (detected by GC-MS) was also observed by DRIFT spectroscopy, being related to the signals at $2380 \mathrm{~cm}^{-1}$ and in the range of $2800-3100 \mathrm{~cm}^{-1}$. The first one is associated to the $\mathrm{CO}_{2},{ }^{38}$ produced in decarboxylation reactions (as consequence of the $\mathrm{C}-\mathrm{C}$ bond cleavage), whereas the wide range is related to the $\mathrm{CH}_{3}$ and $\mathrm{CH}_{2}$ stretching modes, being their intensity proportional to their carbon chain length. The intensity of all these bands is considerably higher in the $\mathrm{Mg}-\mathrm{Zr}$ spectra, suggesting a higher relevance of these side reactions. In good agreement with this hypothesis, there is a continue increase in the band at $3680 \mathrm{~cm}^{-1}$, identified not only as the $\mathrm{OH}$ stretching mode related to the presence of long-chain alcohols, but also as a vibration mode of water. ${ }^{38}$ Besides, there is a band around $730 \mathrm{~cm}^{-1}$, associated with the $\mathrm{CH}_{2}$ rocking mode produced in molecules with four or more $\mathrm{CH}_{2}$ groups, ${ }^{39}$ that only appears in the $\mathrm{Mg}-\mathrm{Zr}$.

The differences between both materials, in both gas and solid phase, can be explained considering the morphological and physicochemical properties of their catalytic 
surfaces. Main results obtained with the different characterization techniques are summarized in Table 1. Concerning to the physisorption results, the surface area obtained with $\mathrm{Mg}-\mathrm{Al}$ was more than three times higher than the area obtained with the Mg-Zr, being both catalysts mesoporous solids. Similar values of pore volume were obtained, whereas $\mathrm{Mg}-\mathrm{Zr}$ has higher pore diameter than $\mathrm{Mg}$-Al. In any case, reported values discard the presence of diffusional limitation. The highest crystallinity was observed in the XRD spectra of $\mathrm{Mg}-\mathrm{Zr}$ (Figure 6), observing more intense and narrower peaks than in the $\mathrm{Mg}$ - $\mathrm{Al}$, being congruent with values obtained in the surface area. In both cases, periclase is the main crystalline phase (JCPDS 45-946; $2 \theta=43,63$ and $78^{\circ}$ ), indicating that a different crystallinity is not the key factor in this reaction. Furthermore, small peaks related to tetragonal zirconia (JCPDS 42-1164; $2 \theta=30^{\circ}$ ) were also distinguished in $\mathrm{Mg}-\mathrm{Zr}$, whereas peaks associated to alumina are not observed in the $\mathrm{Mg}-\mathrm{Al}$, suggesting that this metal is present as amorphous phase in this oxide. In good agreement, XPS analyses reveal a surface content of $\mathrm{Al}$ about $35 \%$ for $\mathrm{Mg}-\mathrm{Al}$, whereas the surface amount of $\mathrm{Zr}$ is much lower. XPS results also indicate higher proportion of oxygen in the surface of $\mathrm{Mg}-\mathrm{Zr}$ (almost $60 \%$ whereas there is only $38 \%$ with the $\mathrm{Mg}-\mathrm{Al}$ ). These atoms correspond to isolate oxygens, $\mathrm{O}^{2-}$, that have been previously reported as the responsible of dehydrations via unimolecular elimination conjugate base $\left(\mathrm{E}_{1 \mathrm{CB}}\right){ }^{9}$ This fact justifies the higher amount of ethylene and diethyl ether obtained in the reaction catalyzed by $\mathrm{Mg}-\mathrm{Zr}$. Besides the high volatility of these compounds, these products cannot be easily observed by DRIFT because their main bands (according to the literature the strongest ones are located at 1444, 2989 and $\left.3106 \mathrm{~cm}^{-1}\right)^{38}$ overlap with other signals related to other main products.

The concentration and strength-distribution of basic and acid sites analyzed by TPD of $\mathrm{CO}_{2}$ and $\mathrm{NH}_{3}$, respectively, (Table 1) contributes to justify the different activities in the 
main route observed with both materials. The 1-butanol formation implies a first dehydrogenation of ethanol, the aldol condensation of the resulting acetaldehyde and two further steps of hydrogenation. According to the literature, ${ }^{10}$ these three reactions are catalyzed by different active sites and there is not good agreement about the key parameter of the whole process.

The dehydrogenation of ethanol requires a good balance between medium strength acid and basic pairs in order to activate the $\mathrm{C}-\mathrm{H}$ bond (acid site), thus it is adsorbed as an ethoxide and then dehydrogenated (basic site). Since both materials show similar medium basicity, being more relevant the differences in the medium acidity, it can be inferred than a minimum basicity/acidity ratio is needed to favor the equilibrium between the proton and the ethoxide adsorbed. Same good distribution is also required in the aldol condensation of two acetaldehyde molecules to obtain the crotonaldehyde. ${ }^{40,41}$ Considering that no significant amounts of this compound are detected in any case, it can be concluded that this compound is quickly transformed into the following intermediates of the main reaction.

Strong basic sites are needed for the last hydrogenation steps of the Guerbet reaction, ${ }^{15}$ justifying that the 1-butanol yield is much higher with Mg-Al. This type of active sites have been also reported as responsible of side-reaction to obtain alcohols with longer chains via crotonaldehyde aldolization. ${ }^{42}$ Despite this competitive effect, the relevance of the oligomerizations is not so high, indicating that the hydrogenation of crotonaldehyde is easier than its condensation.

Concerning to the specific role of the acidity, main differences are related to the weak and medium sites. Desorption temperatures are very similar in both cases, indicating a similar strength, but the concentration of these sites is almost four times higher for 
$\mathrm{Mg}-\mathrm{Zr}$. These sites mainly promote the dehydration of alcohols to olefins via $\mathrm{E}_{2}$ mechanism. ${ }^{9}$ According to the Scheme 1, two different dehydrations to olefins occur in the gas-phase ethanol self-condensation, the ethanol dehydration to ethylene and the crotyl alcohol dehydration to 1,3-butadiene. As consequence, the large amount of ethylene obtained with $\mathrm{Mg}-\mathrm{Zr}$ is the consequence of the coexistence of both dehydration mechanism $\mathrm{E}_{1 \mathrm{CB}}$ and $\mathrm{E}_{2}$, mainly at the highest temperatures. Besides, the acidity is also responsible of the relative high 1,3-butadiene yield obtained with this material at medium-high temperatures. This role is no so evident, mainly at high temperatures, because it is conditioned by the previous steps; but there is a clear competence with the crotyl alcohol hydrogenation at lower temperatures, preventing the 1,3-butadiene appearance. In good agreement, the ratio 1-butanol/1,3-butadiene is four times lower with the $\mathrm{Mg}-\mathrm{Zr}$ than with the $\mathrm{Mg}-\mathrm{Al}(15.9$ and 3.6 at $623 \mathrm{~K}$, for $\mathrm{Mg}-\mathrm{Al}$ and $\mathrm{Mg}-\mathrm{Zr}$, respectively), in same ratio than the acidity differences.

Diethyl ether formation is also produced by dehydration of two ethanol molecules which are firstly coupled, taking place on the same active sites as alcohol hydrogenation and aldol condensation. ${ }^{9,32,41}$ This competition between different reactions implies that ethylene yield was much higher than diethyl ether for any temperature even though dehydration to olefins has a higher activation energy than dehydration to ethers. ${ }^{9}$ The more acid character (which promote the dehydration process) of the $\mathrm{Mg}$ - $\mathrm{Zr}$ catalyst entails that diethyl ether was only significantly observed at high temperatures with this material.

3.3. Stability studies. In order to evaluate the catalyst stability, the evolution of the conversion and selectivity with time on stream was recorded at two different temperatures (673 and $723 \mathrm{~K}$ ). In order to gain further understanding about the deactivation causes, DRIFT spectra at different exposition times were recorded when 
feeding the ethanol-containing gases to the DRIFT chamber. On the other hand, samples used in the fixed bed reactor were characterized in order to determine the importance of the different deactivation causes: sintering, metal leaching and the fouling by a partial or global blockage of the active sites by permanent adsorption of butadiene oligomers or undesired condensation adducts.

Results obtained at $673 \mathrm{~K}$, both in gas phase (Figure 7) and also by DRIFT spectroscopy (Figure 8), suggest that no relevant deactivation was observed at these conditions. Similar conversions, selectivities and carbon balances were obtained with both materials, without observing any significant change in the adsorption modes during the time on stream. Among the differences in the DRIFT spectra between both catalysts, the band at $1655 \mathrm{~cm}^{-1}$, related to polybutadiene formation, ${ }^{43}$ was only weakly observed for the $\mathrm{Mg}-\mathrm{Zr}$ catalyst (Figure $\mathbf{8 b}$ ). In addition the intensity of this band does not increase with reaction time.

Different behavior was observed in gas phase results obtained at $723 \mathrm{~K}$, as it is summarized in Figure 9. At these conditions, a loss of activity was observed for both materials, being more relevant in the case of $\mathrm{Mg}-\mathrm{Zr}$. Thus, conversion decreases from 47.5 to $37.0 \%$ with $\mathrm{Mg}$-Al, and from 45.3 to $23.2 \%$ with $\mathrm{Mg}-\mathrm{Zr}$. Concerning to the carbon balance closure, this parameter increases with the time on stream, reaching final values of 84.2 and $91.4 \%$ for $\mathrm{Mg}-\mathrm{Al}$ and $\mathrm{Mg}-\mathrm{Zr}$, respectively, after 8 hours. Main differences between both materials concern to the product selectivities. In the case of $\mathrm{Mg}-\mathrm{Al}$, the product distribution is not influenced by the catalyst deactivation, suggesting that the active sites for the main reactions are hardly affected by this deactivation. In good agreement with this hypothesis, differences lower than $2 \%$ are observed in selectivities after 1 and 8 hours. On the other hand, $\mathrm{Mg}-\mathrm{Zr}$ results show a relevant decrease in the ethylene selectivity in more than $15 \%$. As consequence of this 
deactivation in the side reaction, there is a relative increase of almost $13 \%$ in the 1-butanol selectivity, resulting into a constant 1-butanol yield of $3 \%$ during all the time tested.

The hypothesis of deactivation by crystallographic changes of the active phases was discarded by analyzing the XRD spectra of materials recovered after 8 hours on stream at $723 \mathrm{~K}$. The comparison between fresh and spent spectra of both materials is detailed in Figure 10. No significant changes were observed in any case, with only a slight decrease in the intensity of periclase peaks of $\mathrm{Mg}$-Al. The decomposition of the initial material as well as the deposition of any crystalline phase that can modify the initial activity is then discarded. Possible changes in the surface morphology were also analyzed by $\mathrm{N}_{2}$ physisorption, obtaining values of 160 and $40 \mathrm{~m}^{2} \cdot \mathrm{g}^{-1}$, for $\mathrm{Mg}-\mathrm{Al}$ and $\mathrm{Mg}-\mathrm{Zr}$, respectively. These values imply a relative decrease twice higher in the case of $\mathrm{Mg}-\mathrm{Zr}$ (respect to their initial values), suggesting a deactivation by deposition of organic deposits, leading to the selective blockage of some active sites. If this deposition is caused by oligomers or large molecules, their adsorption can fully block the pores, justifying the surface area losses.

The assumption of oligomers adsorption was tested by analyzing the evolution of the DRIFT spectra during the same period recorded at similar conditions (Figure 11). As it could be expected, higher changes are observed in the $\mathrm{Mg}-\mathrm{Zr}$ spectra, whereas only a slight increase in almost all the intensities, proportional with the time, is observed with the $\mathrm{Mg}-\mathrm{Al}$. In the case of $\mathrm{Mg}-\mathrm{Zr}$, there is a relevant increase in the intensities of signals in range $600-1200 \mathrm{~cm}^{-1}$ (mainly the band at $750 \mathrm{~cm}^{-1}$ ) and in $2800-3000 \mathrm{~cm}^{-1}$. According to the previous identification, these rises are directly related to an increase in the amount of alcohols with four or more $\mathrm{CH}_{2}$ groups (higher alcohols) permanently adsorbed as alkoxides on the acid sites of the catalytic surface, justifying the decrease of 
the ethylene selectivity during the reaction time as consequence of the acid sites blockage. This deactivation has been previously reported for different reactions involving the presence of heavy alcohols as reactants, products or intermediates. ${ }^{44,45}$ The band associated to polybutadiene $\left(1655 \mathrm{~cm}^{-1}\right)$ was again observed with low intensity with the $\mathrm{Mg}-\mathrm{Zr}$ material at this temperature. However, the intensity of this band remains almost constant during all the period, suggesting that butadiene oligomerization products play a minor role on catalyst deactivation.

In order to identify the products adsorbed on the catalytic surface, spent samples of both catalysts after $8 \mathrm{~h}$ of reaction at $723 \mathrm{~K}$ were recovered and analyzed by thermogravimetry in an oxidant atmosphere. Resulting plots are shown in the supplementary information (Figure S2). In both cases, main peak appears around $790 \mathrm{~K}$ (there are others at lower temperatures related to water and reaction products well identified), suggesting that same or very similar oligomers are deposited on both surfaces. This temperature is considerably higher than the boiling points of the side products detected by GC-MS when the spent materials are extracted with tetrahydrofuran (THF): pentanal with both materials and also 1-nonanol, cresol and 2-ethylphenol with $\mathrm{Mg}-\mathrm{Zr}$, suggesting that the oligomerization of oxygenated compounds follows to heavier and THF-insoluble compounds. Comparing both areas, the signal obtained with $\mathrm{Mg}-\mathrm{Zr}$ corresponds to a $27.4 \%$ of the total loss of mass, whereas it means only $11.2 \%$ when $\mathrm{Mg}$ - $\mathrm{Al}$ is used.

These results justify the highest loss of activity observed with the $\mathrm{Mg}-\mathrm{Zr}$ by the coexistence of two deactivation mechanism: the partial blockage of a greater amount of active sites by the permanent deposition of these oxygen-containing oligomers, generated by successive aldol condensation-dehydration steps, and therefore needing 
both the presence of acid and basic sites. These oligomers present a strong interaction with acid sites (formation of alkoxides) and also lead to typical fouling effects.

\section{CONCLUSIONS}

The ethanol condensation over mixed oxides for obtaining butanol is studied in this work. The combination of fixed bed reactor experiments, in situ DRIF T measurement and conventional off-site characterization techniques allows to understand the reaction mechanisms, as well as the identification of the main deactivation causes.

Different temperatures, as well different residence times, were tested, concluding that best results are obtained using $150 \mathrm{mg}$ of catalyst and temperatures from 673 to $723 \mathrm{~K}$ : $37.1 \%$ of ethanol conversion with $33.4 \%$ of 1-butanol selectivity. Similar conversion was obtained with $\mathrm{Mg}-\mathrm{Zr}$ (30.6\%), but this catalyst is less selective for the 1-butanol (only $8 \%$ at these conditions), increasing the relevance of compounds produced by dehydration steps (ethylene, 1,3-butadiene and diethyl ether). In both cases, carbon balances higher than $70 \%$ were obtained at optimum conditions.

A different distribution of acid and basic sites was identified as the main justification of their different results, highlighting the negative role of acidity, mainly in the $\mathrm{Mg}-\mathrm{Zr}$, promoting the permanent adsorption of crotonaldehyde, crotyl alcohol and butanal, mainly at high temperatures, as it was observed by DRIFT spectroscopy.

The deactivation of these materials was deep study, analyzing the evolution of both, gas phase and catalytic surface, during 8 hours at different temperatures. No significant loss of stability with any of these materials was observed at $673 \mathrm{~K}$ and lower temperatures. On the other hand, in spite of the catalyst used, a partial deactivation was observed at $723 \mathrm{~K}$, with significant decrease in the ethanol conversion, $(22.1$ and $13.7 \%$ with $\mathrm{Mg}-\mathrm{Zr}$ and $\mathrm{Mg}-\mathrm{Al}$, respectively). DRIFT spectroscopy analyses conclude that this deactivation is due to the permanent adsorption of some intermediates as well as the 
formation of oxygenated oligomers with more than four carbon atoms, presenting a strong interaction with the catalyst acid sites (surface alkoxides).

\section{ASSOCIATED CONTENT}

\section{Supporting Information}

Table S1

Figure S1

Figure S2

This material is available free of charge via the Internet at http://pubs.acs.org.

\section{AUTHOR INFORMATION}

\section{Corresponding Author}

*E-mail: sordonez@uniovi.es

\section{Notes}

The authors declare no competing financial interest.

\section{ACKNOWLEDGMENTS}

The authors would like to acknowledge financial support for this work from the Ministry of Economy and Competitiveness of the Spanish Government (Contract CTQ2014-52956-C3-1-R) and from the Government of the Principality of Asturias (Contract FC-15-GRUPIN14-078). Jorge Quesada would also like to thank the Government of the Principality of Asturias for his Ph.D. fellowship of the Severo Ochoa Program (PA-14-PF-BP14-105). Jennifer Cueto is acknowledged by her cooperation in the TG analyses.

\section{REFERENCES}

(1) Breitkreuz, K.; Menne, A.; Kraft, A. Biofuels, Bioprod. Bioref. 2014, 8, 504-515. 
(2) Renewable Fuels Association analysis of public and private estimates, Industry Statistics: 2015 World Fuel Ethanol Production, Renewable Fuels Association Website. http://www.ethanolrfa.org/resources/industry/statistics/\#1454098996478715d404-e546 (accessed May 27, 2016).

(3) Kozlowski, J. T.; Davis, R. J. ACS Catal. 2013, 3, 1588-1600.

(4) Makshina, E. V.; Dusselier, M.; Janssens, W.; Degrève, J.; Jacobs, P. A.; Sels, B. F. Chem. Soc. Rev. 2014, 43, 7917-7953.

(5) Silvester, L.; Lamonier, J. F., Faye, J.; Capron, M.; Vannier, R. N.; Lamonier, C.; Dubois, J. L.; Couturier, J. L.; Calais, C.; Dumeignil, F. Catal. Sci. Technol. 2015, 5, 2994-3006.

(6) Schwartz, T. J.; Shanks, B. H.; Dumesic, J. A. Curr. Opin. Biotech. 2016, 38, $54-62$.

(7) Sun, J.; Wang, Y. ACS Catal. 2014, 4, 1078-1090.

(8) Kamiński, W.; Tomczak, E.; Górak, A. Ecol. Chem. Eng. S 2011, 18, 31-37.

(9) Di Cosimo, J. I.; Apesteguía, C. R.; Ginés, M. J. L.; Iglesia, E. J. Catal. 2000, $190,261-275$.

(10) Ginés, M. J. L.; Iglesia, E. J. Catal. 1998, 176, 155-172.

(11) Hilmen, A. M.; Xu, M.; Ginés, M. J. L.; Iglesia, E. Appl. Catal., A 1998, 169, $355-372$.

(12) Billig, E. In Kirk-Othmer Encyclopedia of Chemical Technology, 5th ed.; Seidel, A., Kroschwitz, J. I., Eds.; Wiley-Interscience: New York, 2007; Vol. 4, p. 398.

(13) Fuchs, O.; Querfurth, W. U.S. Patent 19924801935.

(14) Burgoyne, E. E. U.S. Patent 26456671953.

(15) León, M.; Díaz, E.; Ordóñez, S. Catal. Today 2011, 164, 436-442.

(16) Kozlowski, J. T.; Davis, R. J. J. Energy Chem. 2013, 22, 58-64. 
(17) Ogo, S.; Onda, A.; Iwasa, K.; Fukuoka, A.; Yanagisawa, J. J. Catal. 2012, 296, 24-30.

(18) Ho, C. R.; Shylesh, S.; Bell, A. T. ACS Catal. 2016, 6, 939-948.

(19) Young, Z. D.; Hanspal, S.; Davis, R. J. ACS Catal. 2016, 6, 3193-3202.

(20) Hanspal, S.; Young, Z. D.; Shou, H.; Davis, R. J. ACS Catal. 2015, 5, 1737 1746.

(21) Birky, T. W.; Kozlowski, J. T.; Davis, R. J. J. Catal. 2013, 298, 130-137.

(22) Chieregato, A.; Ochoa, J. V.; Bandinelli, C.; Fornasari, G.; Cavani, F.; Mella, M. ChemSusChem 2015, 8, 377-388.

(23) Angelici, C.; Meirer, F.; van der Eerden, A. M. J.; Schaink, H. L.; Goryachev, A.; Hofmann, J. P.; Hensen, E. J. M.; Weckhuysen, B. M.; Bruijnincx, P. C. A. ACS Catal. 2015, 5, 6005-6015.

(24) Marcu, I.C.; Tanchoux, N.; Fajula, F.; Tichit, D. Catal. Lett. 2013, 143, 23-30.

(25) Tsuchida, T.; Sakuma, S.; Takeguchi, T.; Ueda, W. Ind. Eng. Chem. 2006, 45, $8634-8642$.

(26) Scalbert, J.; Thibault-Starzyk, F.; Jacquot, R.; Morvan, D.; Meunier, F. J. Catal. 2014, 311, 28-32.

(27) Moteki, T.; Flaherty, D. W. ACS Catal. doi:10.1021/acscatal.6b00556

(28) Iton, L. E.; Choi, I.; Desjardins, J. A.; Maroni, V. A. Zeolites 1989, 9, 535-538.

(29) Polster, C. S.; Nair, H.; Baertsch, C. D. J. Catal. 2009, 266, 308-319.

(30) Río, E.; Collins, S. E.; Aguirre, A.; Chen, X.; Delgado, J. J.; Calvino, J. J.; Bernal, S. J. Catal. 2014, 316, 210-218.

(31) Quesada, J.; Faba, L.; Díaz. E.; Bennici, S.; Auroux, A., Ordóñez, S. J. Catal. 2015, 329, 1-9.

(32) Faba, L.; Díaz, E.; Ordóñez, S. Appl. Catal., B 2013, 142-143, 387-395. 
(33) Davis, M. E.; Davis, R. J. In Fundamentals of Chemical Reaction Engineering, 1st ed., Jones, E. A., Ed.; McGraw Hill: New York, 2003; p. 190-205.

(34) Sun, J.; Zhu, K.; Gao, F.; Wang, C.; Liu, J. J. Am. Chem. Soc. 2011, 133, 1109611099.

(35) Jordison, T. L.; Peereboom, L.; Miller, D. J. Ind. Eng. Chem. Res. doi: 10.1021/acs.iecr.6b00700.

(36) Rekoske, J. E.; Barteau, M. A. Ind. Eng. Chem. Res. 2011, 50, 41-51.

(37) Shylesh, S.; Gokhale, A. A.; Scown, C. D.; Kim, D.; Ho, C. R.; Bell, A. T. ChemSusChem 2016, 9, 1462-1472.

(38) Shimanouchi, T. Tables of Molecular Vibrational Frequencies Consolidated Volume I, National Bureau of Standards, 1972, 1-160.

(39) Smith, B. C. In Infrared Spectral Interpretation: A Systematic Approach, 1st ed.; CRC Press LLC: Florida, 1999; p. 36.

(40) Sádaba, I.; Ojeda, M.; Mariscal, R.; Fierro, J. L. G.; López-Granados, M. Appl. Catal., B 2011, 101, 638-648.

(41) Barrett, C. J.; Chheda, J. N.; Huber, G. W.; Dumesic, J. A. Appl. Catal., B 2006, $66,111-118$.

(42) Ordóñez, S.; Díaz, E.; León, M.; Faba, L. Catal. Today 2011, 167, 71-76.

(43) Berndt, H.; Landmesser, H. J. Mol. Catal. A: Chem. 2003, 197, 245-253.

(44) de Klerk, A.; Furimsky, E. in Catalysis in the Refining of Fischer-Tropsch Syncrude; Spivey, J. J., Ed.; RSC Publishing: Cambridge, 2010; RSC Catalysis Series No. 4, p. 136.

(45) Leckel, D. Energ. Fuel 2007, 21, 662-667. 


\section{TABLE CAPTION}

Table 1. Main results of the fresh catalysts characterization: morphological properties, density and distribution of the acid and basic sites, XPS $\mathrm{O}^{1 \mathrm{~s}}$ binding energy, and XPS surface composition.

\section{SCHEME CAPTION}

Scheme 1. Proposed reaction mechanism for the ethanol gas-phase condensation., ${ }^{3,9,15-17}$ Symbols: (A) ethanol; (B) acetaldehyde; (C) crotonaldehyde; (D) crotyl alcohol; (E) butanal; (F) 1-butanol; (G) 1,3-butadiene; (H) ethylene; (I) diethyl ether; (J) ethyl acetate.

\section{FIGURE CAPTION}

Figure 1. Comparison of ethanol conversion (a) and 1-butanol yields (b) obtained as function of the temperature using different WHSV (mass of $\mathrm{Mg}-\mathrm{Al}$ as catalyst). Numbers over the conversion bars indicate the carbon balance closure in terms of percentage

Figure 2. Results of the gas phase ethanol self-condensation catalyzed by $150 \mathrm{mg}$ of Mg-Al at different temperatures. Symbols correspond to ethanol conversion ( $\mathbf{a})$ and carbon balance ( $\mathbf{\Lambda})$. Bars correspond to selectivities of ethylene (purple); acetaldehyde (yellow); 1-butanol (pink); 1,3-butadiene (green) and others (grey). "Others" includes minority compounds (crotonaldehyde, crotyl alcohol, butanal, diethyl ether and ethyl acetate).

Figure 3. Distribution of minority compounds obtained in the ethanol self-condensation in gas phase catalyzed by $\mathrm{Mg}-\mathrm{Al}$ (filled bars) and $\mathrm{Mg}-\mathrm{Zr}$ (striped bars) as function of 
the temperature. Symbols: crotonaldehyde (red); crotyl alcohol (blue); butanal (pink); diethyl ether (grey); ethyl acetate (green).

Figure 4. Results of the gas phase ethanol self-condensation catalyzed by $150 \mathrm{mg}$ of $\mathrm{Mg}-\mathrm{Zr}$ at different temperatures. (See figure 2 for codes).

Figure 5. Evolution with the temperature of the characteristic bands of adsorbed compounds in the ethanol gas-phase condensation when (a) $\mathrm{Mg}-\mathrm{Al}$ or (b) $\mathrm{Mg}-\mathrm{Zr}$ is used as catalyst.

Figure 6. XRD diffractograms of: (a) $\mathrm{Mg}-\mathrm{Zr}$, and (b) $\mathrm{Mg}-\mathrm{Al}$.

Figure 7. Stability analyses at $673 \mathrm{~K}$ when reaction is catalyzed by (a) $\mathrm{Mg}-\mathrm{Al}$, and (b) Mg-Zr. (See figure 2 for codes).

Figure 8. Evolution of the species adsorbed on the catalytic surface of (a) $\mathrm{Mg}-\mathrm{Al}$ and (b) $\mathrm{Mg}-\mathrm{Zr}$ as function of the reaction time when the reaction is carried out at $673 \mathrm{~K}$.

Figure 9. Stability analyses at $723 \mathrm{~K}$ when reaction is catalyzed by (a) $\mathrm{Mg}-\mathrm{Al}$, and (b) Mg-Zr. (See figure 2 for codes).

Figure 10. XRD spectra of fresh and spent materials recovered after 8 hours of ethanol gas-phase condensation at $723 \mathrm{~K}$. (a) $\mathrm{Mg}$-Al; (b) Mg-Zr. (See figure 6 for peaks identification).

Figure 11. Evolution of the species adsorbed on the catalytic surface of (a) $\mathrm{Mg}-\mathrm{Al}$ and (b) $\mathrm{Mg}-\mathrm{Zr}$ as function of the reaction time when the reaction is carried out at $723 \mathrm{~K}$. 
Table 1. Main results of the fresh catalysts characterization: morphological properties, density and distribution of the acid and basic sites, XPS $\mathrm{O}^{1 \mathrm{~s}}$ binding energy, and XPS surface composition.

\begin{tabular}{|c|c|c|c|c|c|c|c|c|c|c|c|c|c|c|}
\hline \multirow{2}{*}{ Catalyst } & \multicolumn{3}{|c|}{ Morphological properties } & \multicolumn{3}{|c|}{ Acid sites $\left(\mu \mathrm{mol} \mathrm{g}{ }^{-1}\right),[\mathrm{T}(\mathrm{K})]$} & \multicolumn{3}{|c|}{ Basic sites $\left(\mu \mathrm{mol} \mathrm{g} \mathrm{g}^{-1}\right),[\mathrm{T}(\mathrm{K})]$} & \multirow{2}{*}{$\begin{array}{c}\text { XPS } \\
\mathrm{O}^{1 \mathrm{~s}} \mathrm{~B} . \mathrm{E} . \\
(\mathrm{eV})\end{array}$} & \multicolumn{4}{|c|}{$\begin{array}{c}\text { XPS surface composition } \\
(\%)\end{array}$} \\
\hline & $\begin{array}{c}\mathrm{S} \\
\left(\mathrm{m}^{2} \mathrm{~g}^{-1}\right)\end{array}$ & $\begin{array}{l}\mathrm{D}_{\mathrm{p}} \\
(\AA)\end{array}$ & $\begin{array}{c}\mathrm{V}_{\mathrm{p}} \\
\left(\mathrm{cm}^{3} \mathrm{~g}^{-1}\right)\end{array}$ & weak & medium & strong & weak & medium & strong & & $\mathrm{Mg}$ & $\mathrm{Al}$ & $\mathrm{Zr}$ & $\mathrm{O}$ \\
\hline $\mathrm{Mg}-\mathrm{Al}$ & 226 & 135 & 0.74 & $\begin{array}{c}11.3 \\
{[345,370]}\end{array}$ & $\begin{array}{l}12.5 \\
{[450]}\end{array}$ & $\begin{array}{c}41.8 \\
{[630,800]}\end{array}$ & $\begin{array}{c}49.7 \\
{[340]}\end{array}$ & $\begin{array}{c}71.7 \\
{[400]}\end{array}$ & $\begin{array}{c}238.6 \\
{[630,670,800]}\end{array}$ & 528.8 & 26.9 & 34.7 & - & 38.4 \\
\hline $\mathrm{Mg}-\mathrm{Zr}$ & 77 & 305 & 0.80 & $\begin{array}{c}52.0 \\
{[360]}\end{array}$ & $\begin{array}{c}41.3 \\
{[440]}\end{array}$ & $\begin{array}{c}47.2 \\
{[630,750]}\end{array}$ & $\begin{array}{c}34.7 \\
{[380]}\end{array}$ & $\begin{array}{c}68.7 \\
{[450]}\end{array}$ & $\begin{array}{c}52.5 \\
{[627]}\end{array}$ & 529.1 & 41.0 & - & 0.4 & 58.6 \\
\hline
\end{tabular}




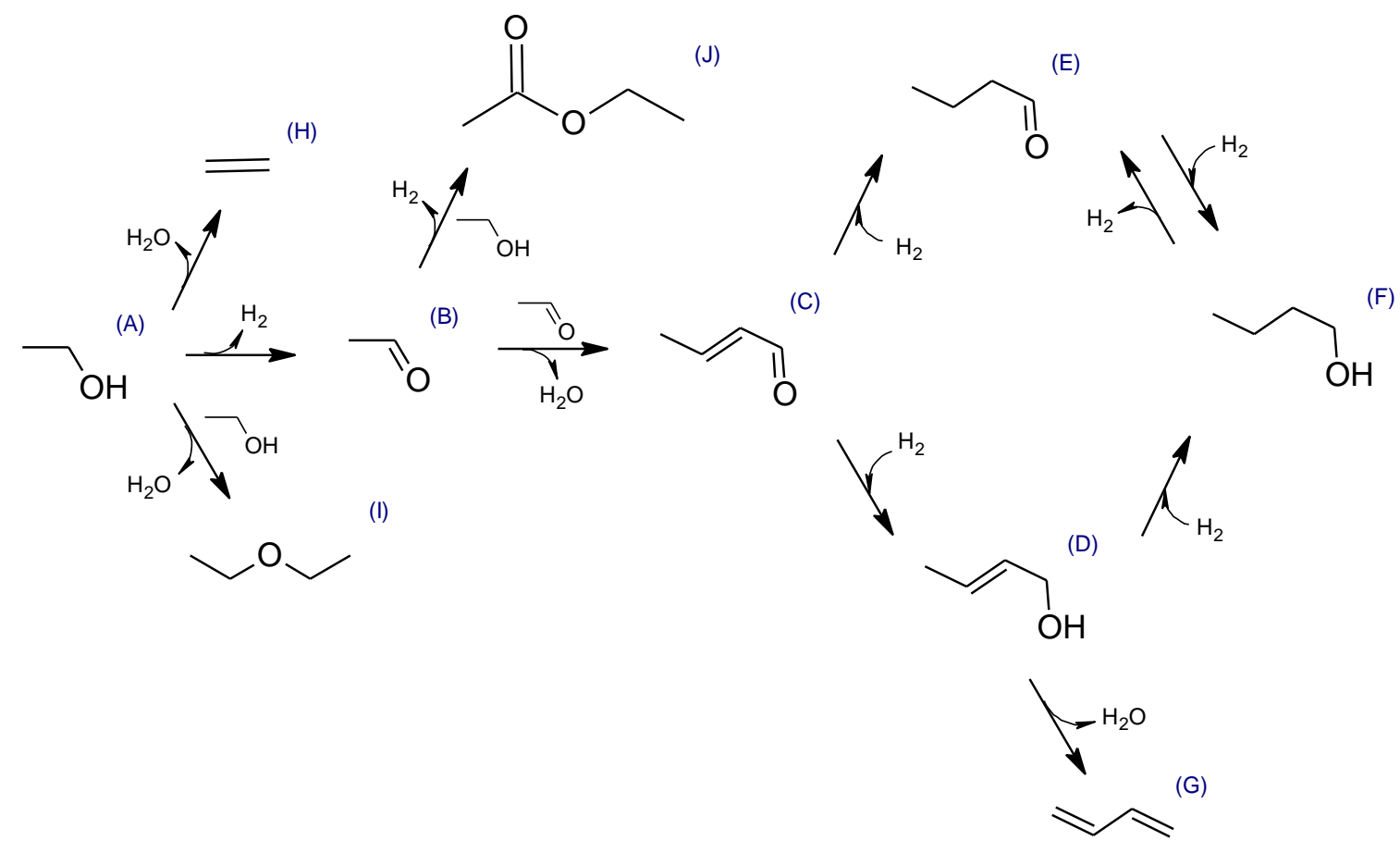

Scheme 1. Proposed reaction mechanism for the ethanol gas-phase condensation. ${ }^{5,9,15-17}$

Symbols: (A) ethanol; (B) acetaldehyde; (C) crotonaldehyde; (D) crotyl alcohol; (E) butanal; (F) 1-butanol; (G) 1,3-butadiene; (H) ethylene; (I) diethyl ether; (J) ethyl acetate. 


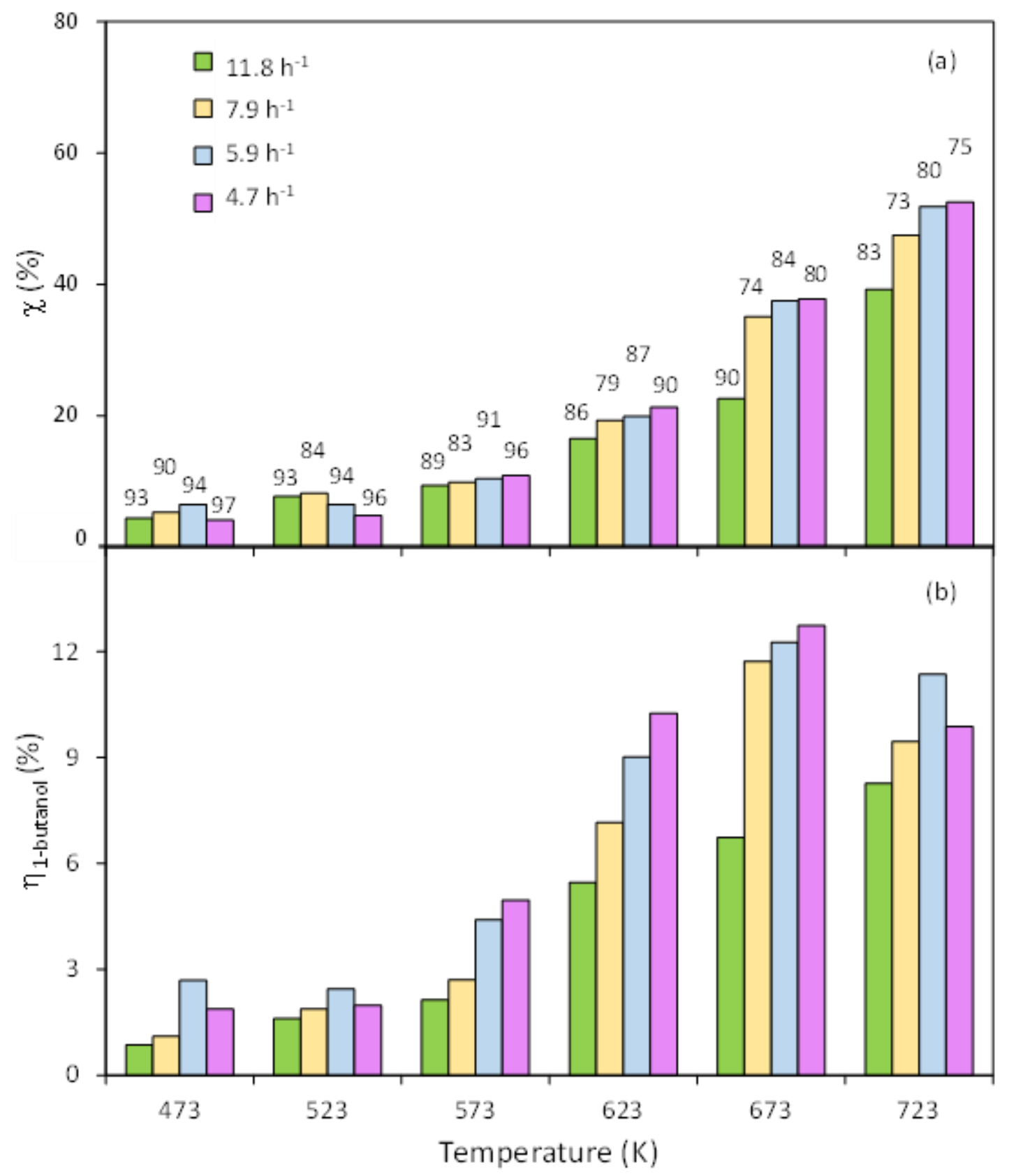

Figure 1. Comparison of ethanol conversion (a) and 1-butanol yields (b) obtained as function of the temperature using different WHSV (mass of Mg-Al as catalyst). Numbers over the conversion bars indicate the carbon balance closure in terms of percentage 


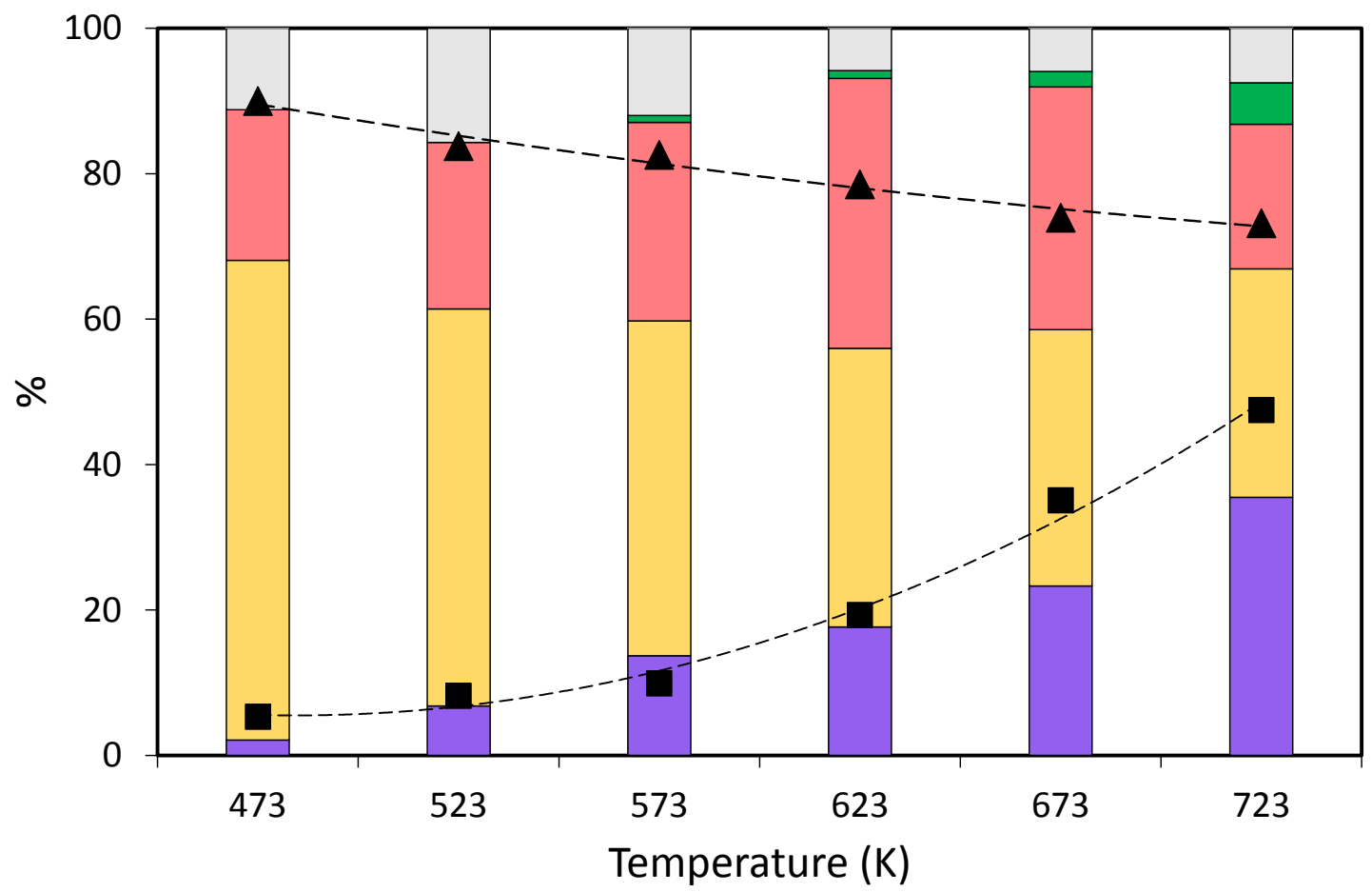

Figure 2. Results of the gas phase ethanol self-condensation catalyzed by $150 \mathrm{mg}$ of $\mathrm{Mg}-\mathrm{Al}$ at different temperatures. Symbols correspond to ethanol conversion (a) and carbon balance ( $\boldsymbol{\Delta})$. Bars correspond to selectivities of ethylene (purple); acetaldehyde (yellow); 1-butanol (pink); 1,3-butadiene (green) and others (grey). "Others" includes minor reaction products (crotonaldehyde, crotyl alcohol, fshfbutanal, diethyl ether and ethyl acetate) 


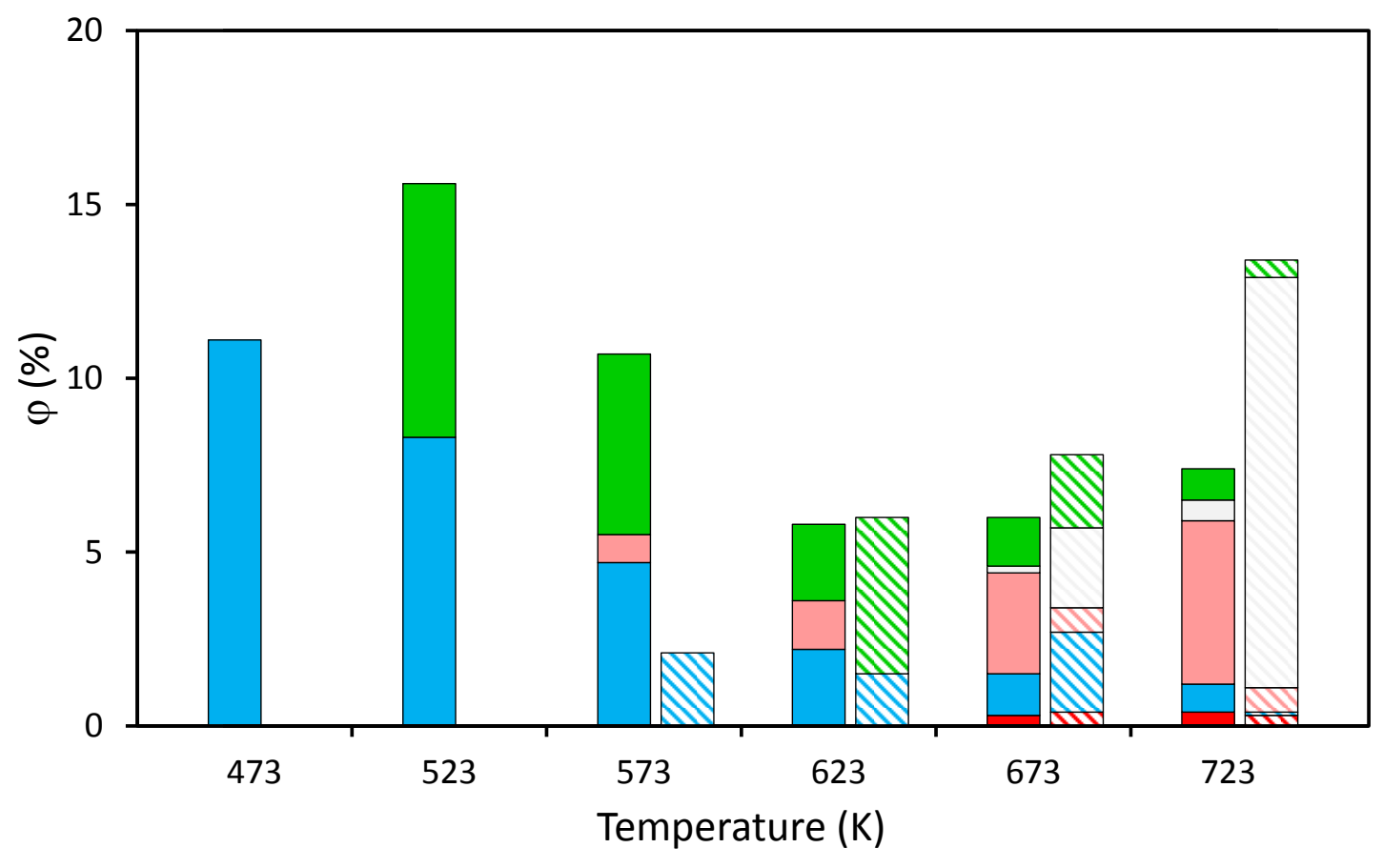

Figure 3. Distribution of minority compounds obtained in the ethanol self-condensation in gas phase catalyzed by $\mathrm{Mg}-\mathrm{Al}$ (filled bars) and $\mathrm{Mg}-\mathrm{Zr}$ (striped bars) as function of the temperature. Symbols: crotonaldehyde (red); crotyl alcohol (blue); butanal (pink); diethyl ether (grey); ethyl acetate (green). 


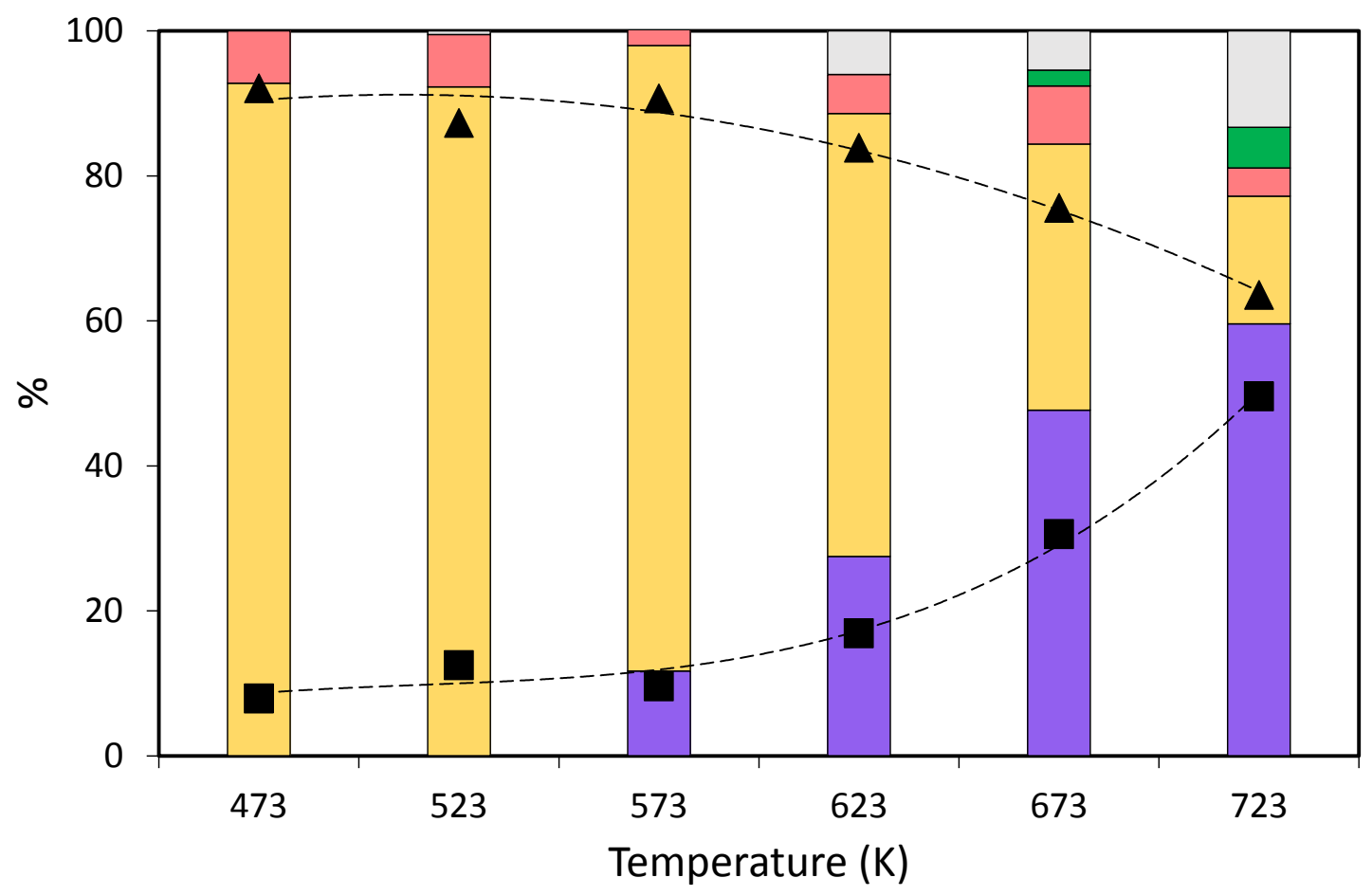

Figure 4. Results of the gas phase ethanol self-condensation catalyzed by $150 \mathrm{mg}$ of $\mathrm{Mg}-\mathrm{Zr}$ at different temperatures. (See figure 2 for codes). 


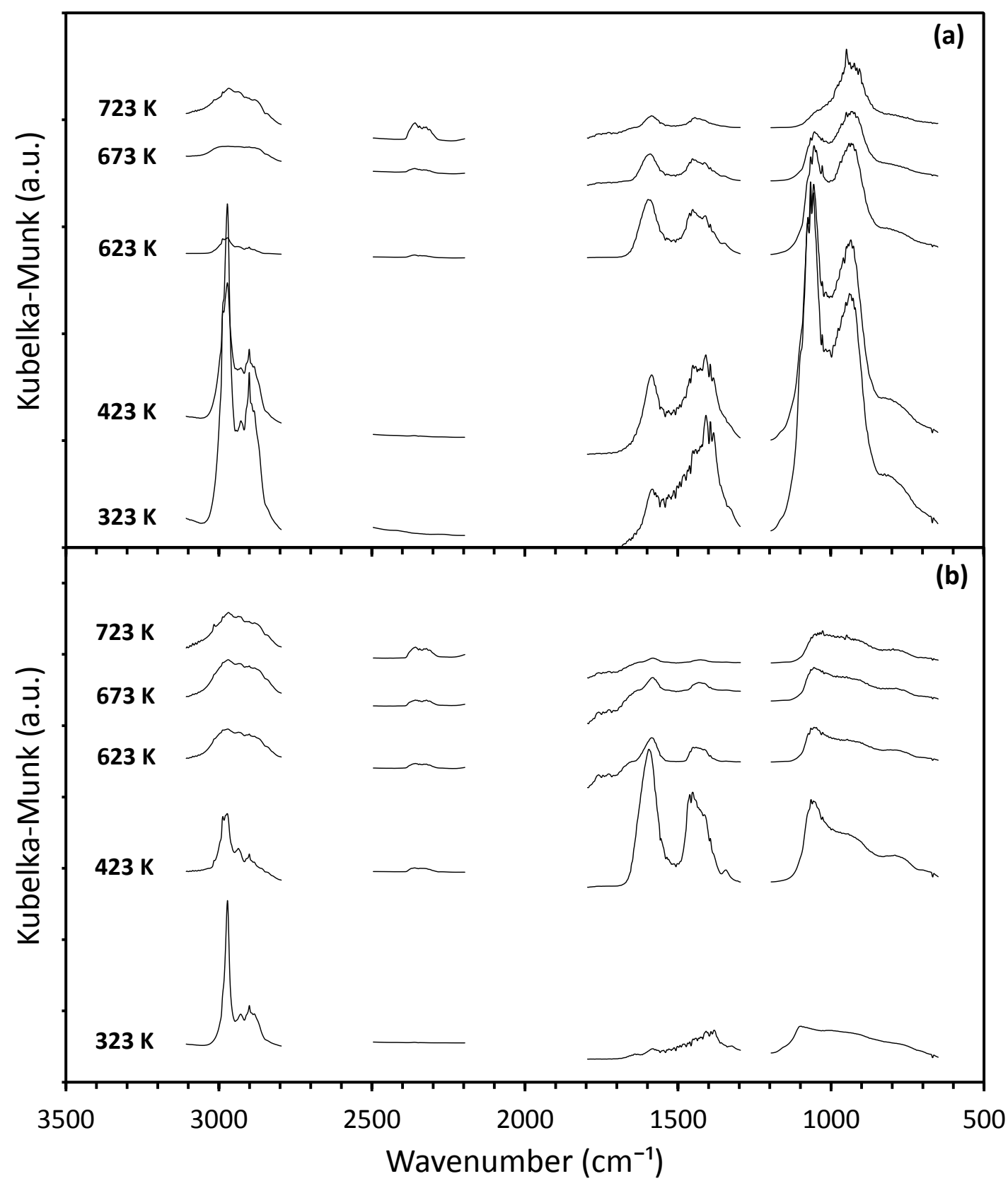

Figure 5. Evolution with the temperature of the characteristic bands of adsorbed compounds in the ethanol gas-phase condensation when (a) $\mathrm{Mg}-\mathrm{Al}$ or (b) $\mathrm{Mg}-\mathrm{Zr}$ is used as catalyst. 


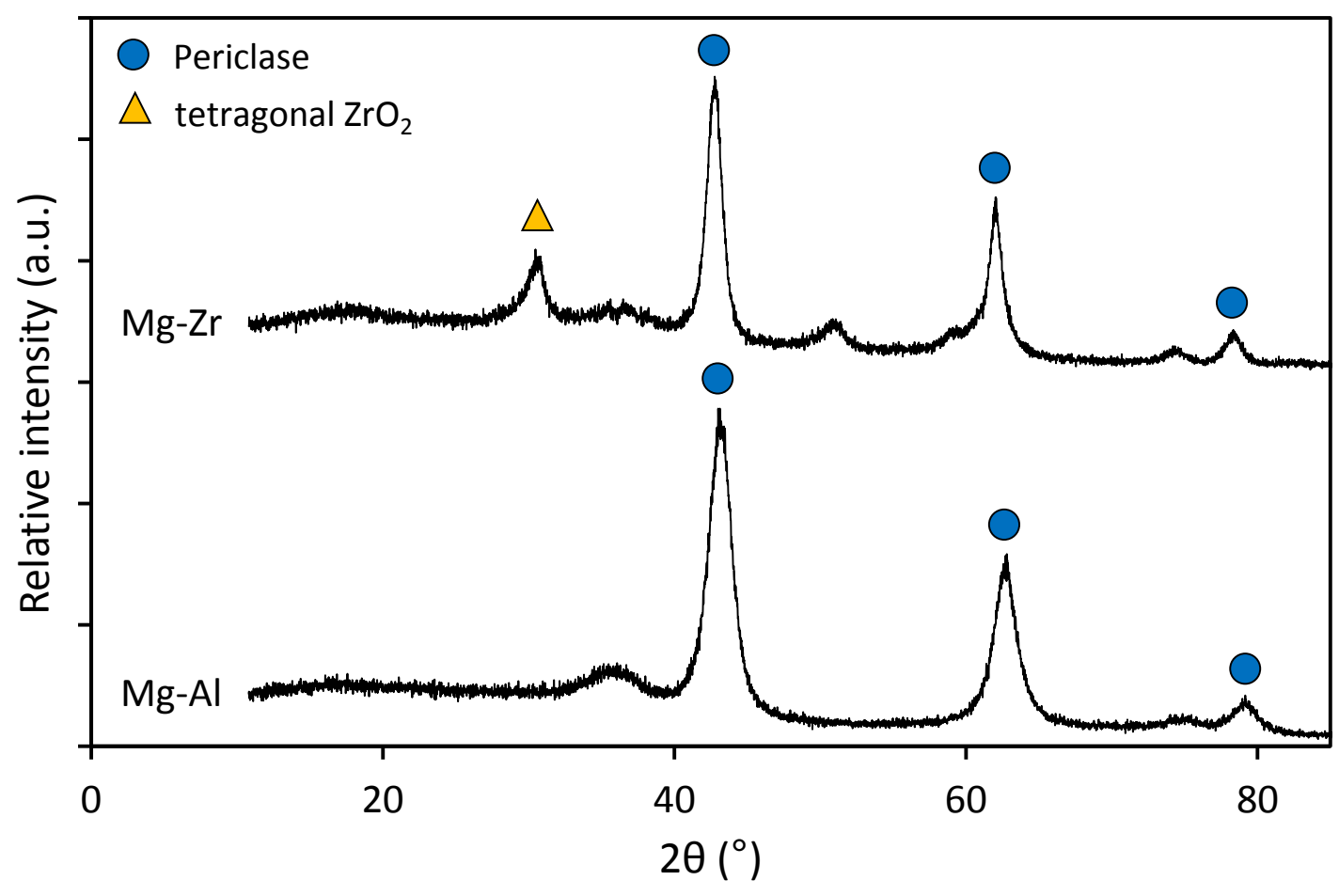

Figure 6. XRD diffractograms of: (a) $\mathrm{Mg}-\mathrm{Zr}$, and (b) $\mathrm{Mg}-\mathrm{Al}$. 
(a)

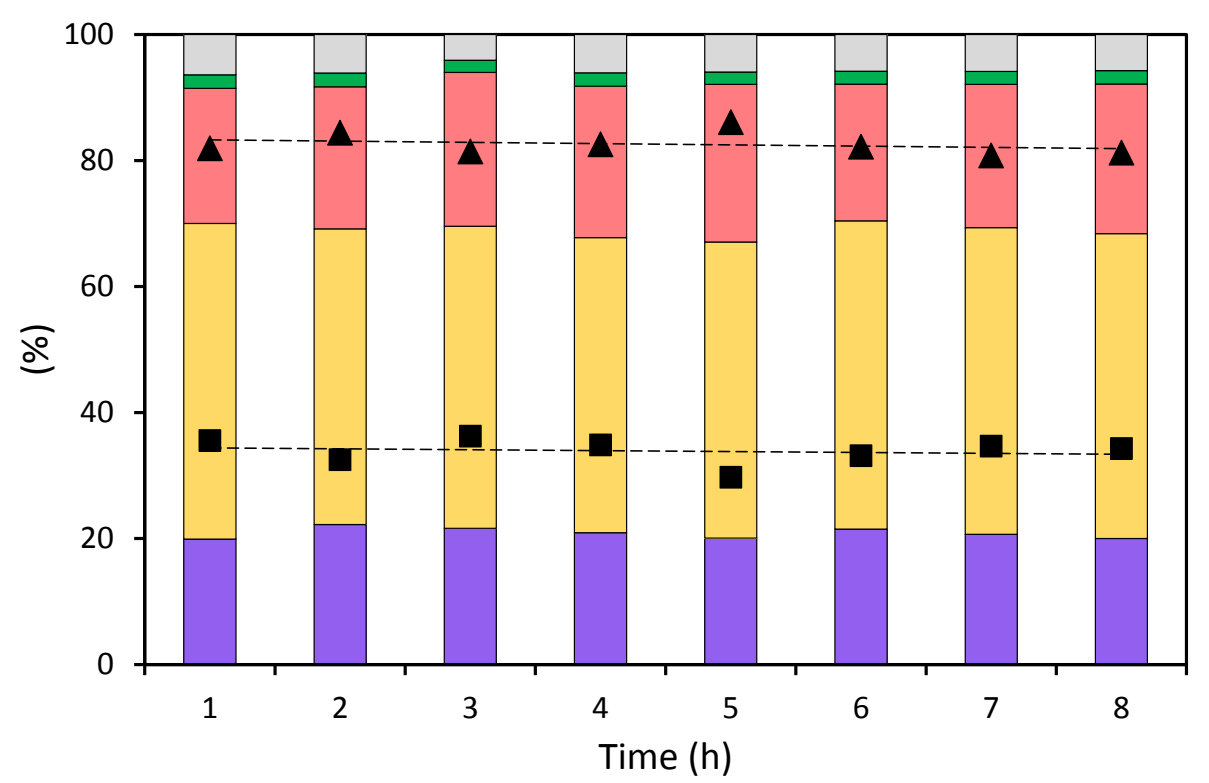

(b)

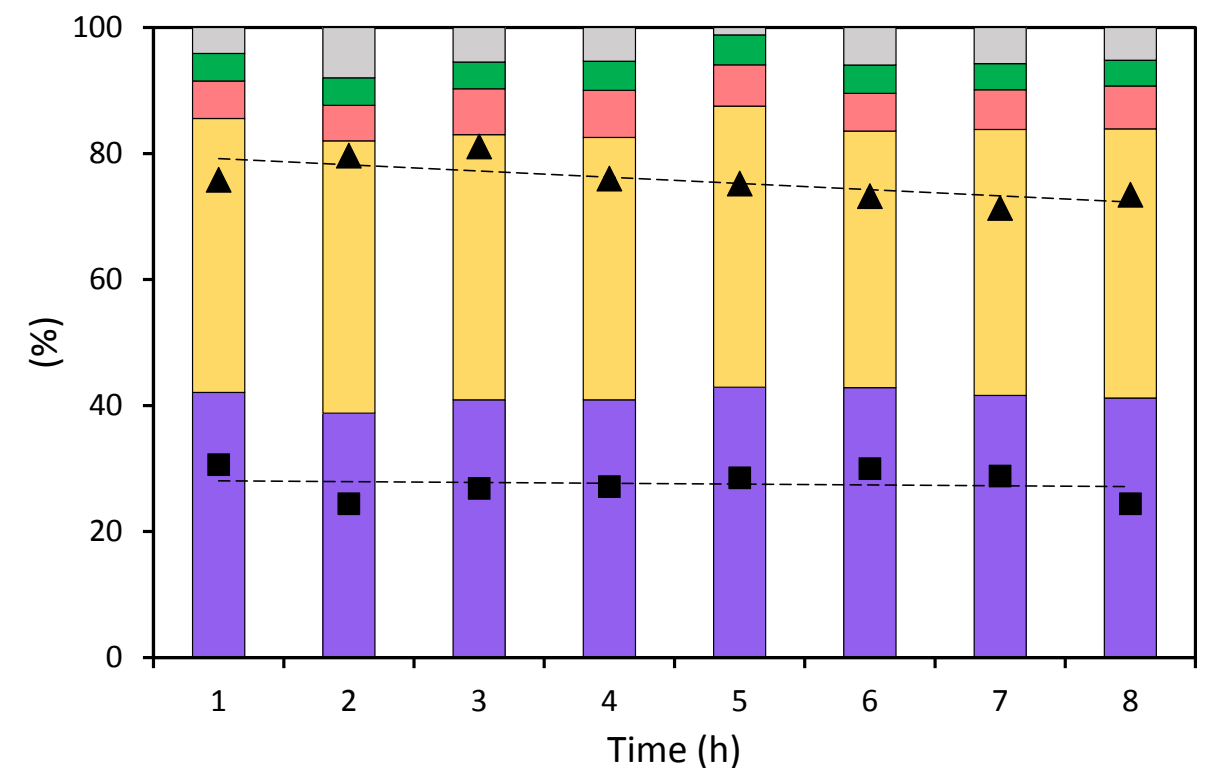

Figure 7. Stability analyses at $673 \mathrm{~K}$ when reaction is catalyzed by (a) Mg-Al, and (b) Mg-Zr. (See figure 2 for codes). 

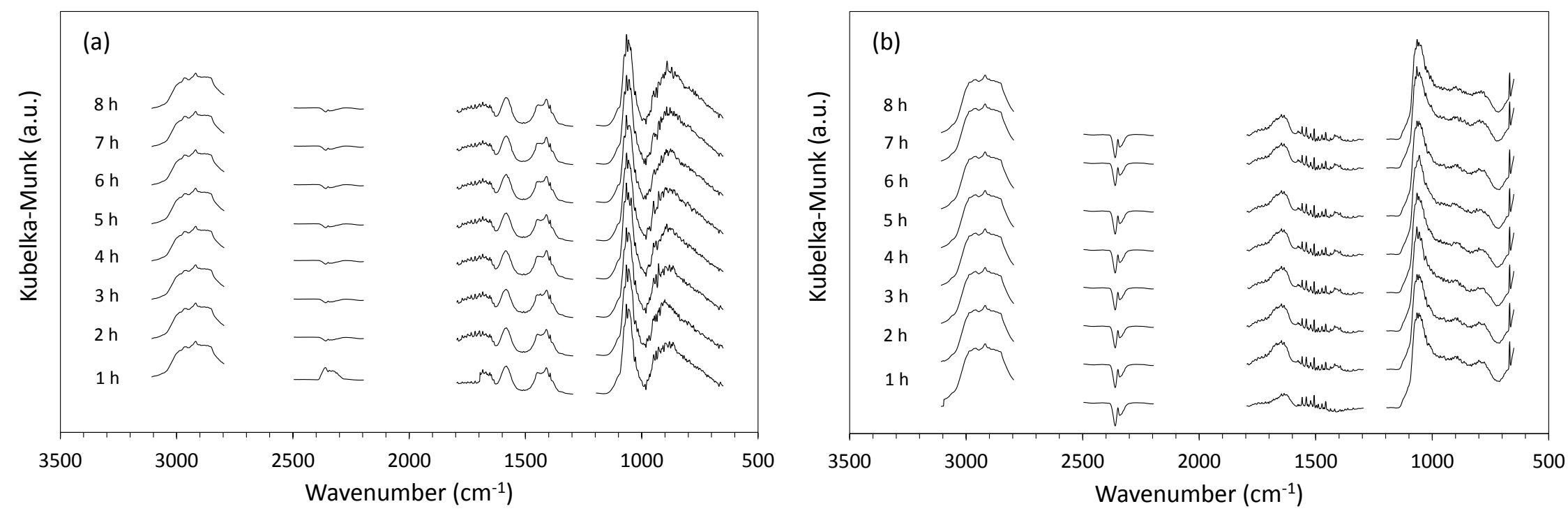

Figure 8. Evolution of the species adsorbed on the catalytic surface of (a) $\mathrm{Mg}-\mathrm{Al}$ and (b) $\mathrm{Mg}-\mathrm{Zr}$ as function of the reaction time when the reaction is carried out at $673 \mathrm{~K}$. 
(a)

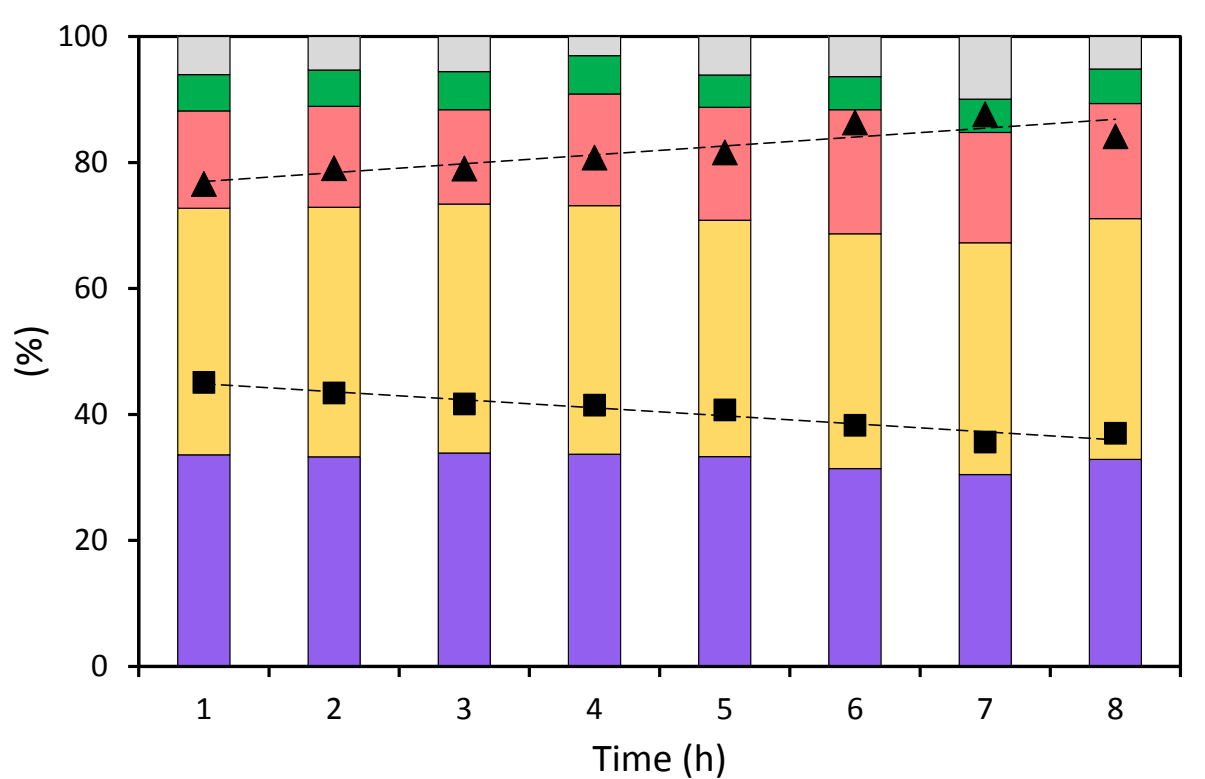

(b)

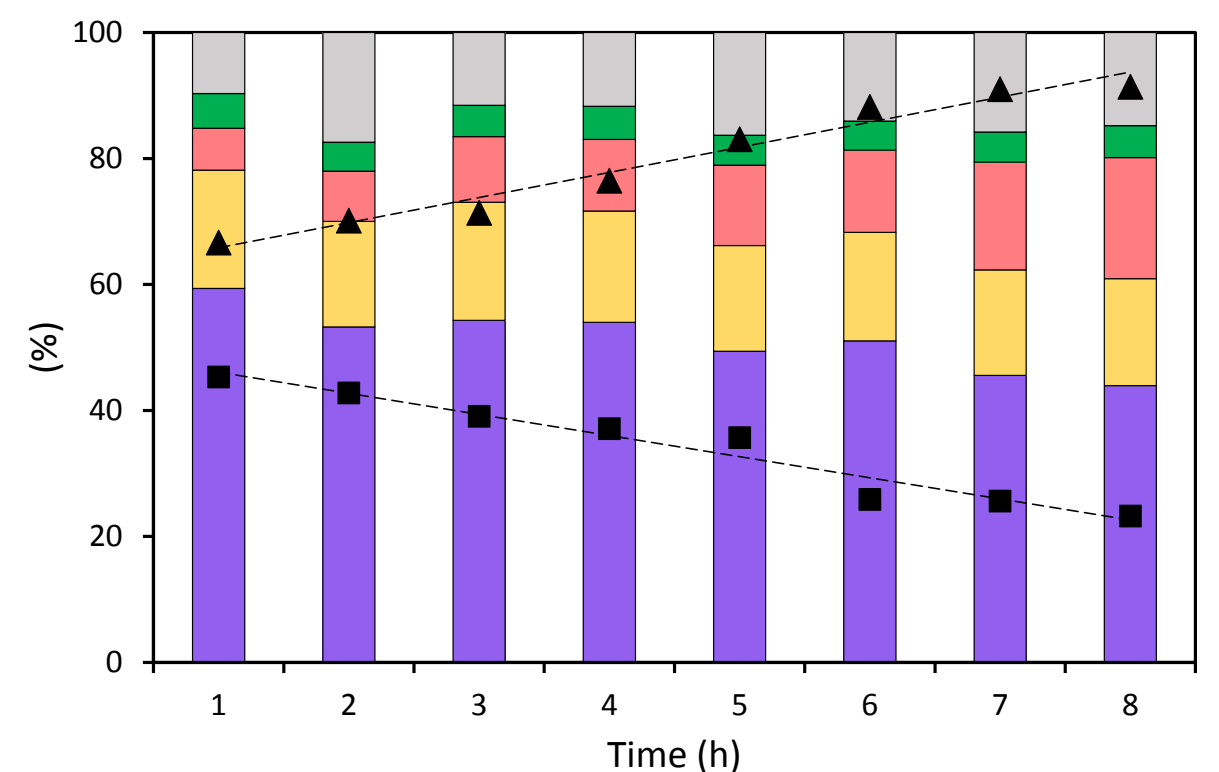

Figure 9. Stability analyses at $723 \mathrm{~K}$ when reaction is catalyzed by (a) Mg-Al, and (b) Mg-Zr. (See figure 2 for codes). 

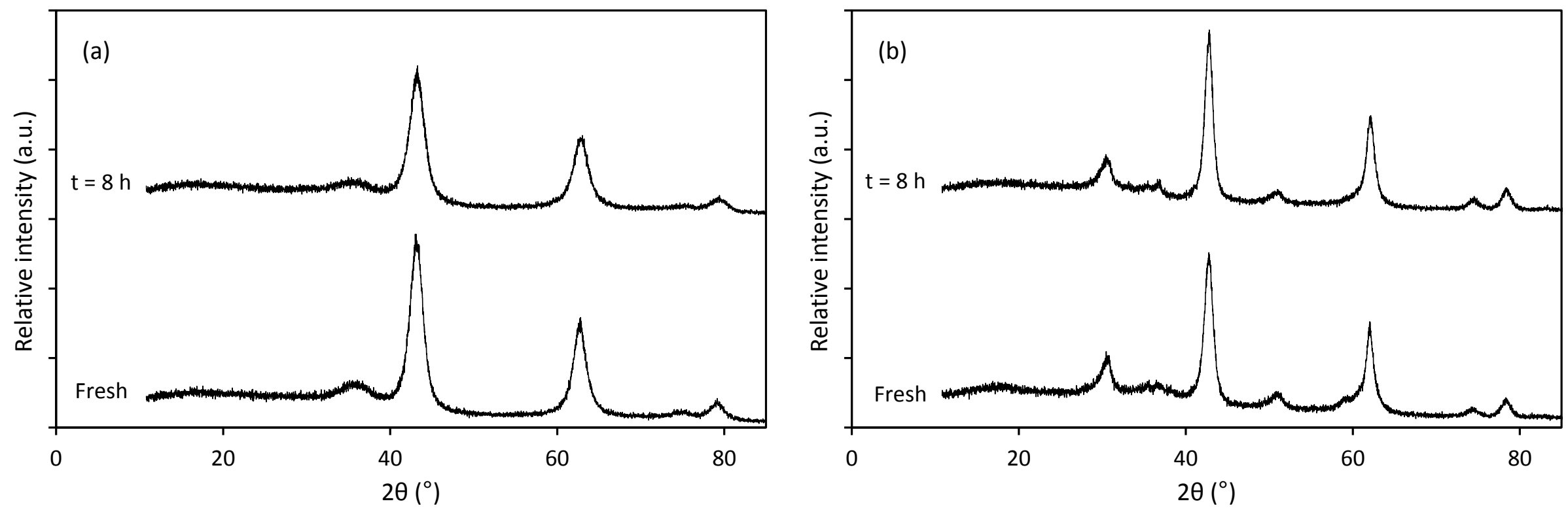

Figure 10. XRD spectra of fresh and spent materials recovered after 8 hours of ethanol gas-phase condensation at $723 \mathrm{~K}$. (a) Mg-Al; (b) Mg-Zr.

(See figure 6 for peaks identification). 

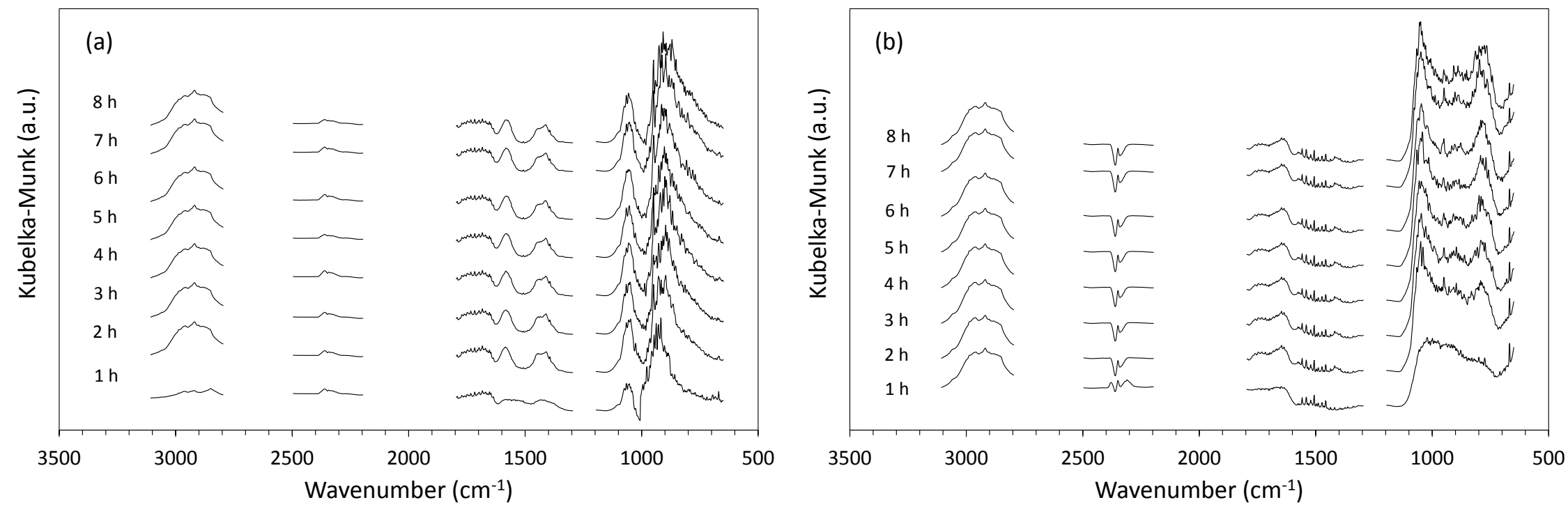

Figure 11. Evolution of the species adsorbed on the catalytic surface of (a) $\mathrm{Mg}-\mathrm{Al}$ and (b) $\mathrm{Mg}-\mathrm{Zr}$ as function of the reaction time when the reaction is carried out at $723 \mathrm{~K}$. 


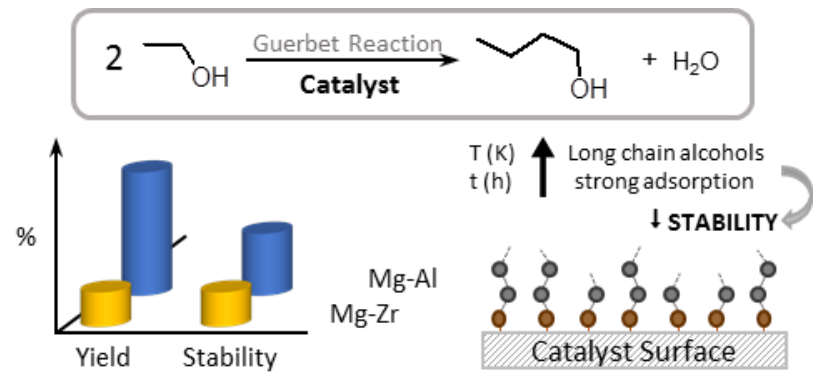

Role of the surface intermediates in the activity and stability of basic mixed oxides in ethanol condensation 